WILENMANN, Javier. “Contra las prácticas argumentativas de apelación a la "teoría de la pena" en la dogmática penal".

Polít. crim. Vol. 12, No 24 (Diciembre 2017), Art. 4, pp. 754-785.

[http://www.politicacriminal.cl/Vol_12/n_24/Vol12N24A4.pdf]

\title{
Contra las prácticas argumentativas de apelación a la "teoría de la pena" en la dogmática penal
}

\section{Against the tendency to make use of the "theory of punishment" in the legal construction of the criminal law}

\author{
Javier Wilenmann von Bernath* \\ Dr. Iur. Albert-Ludwig Universität Freiburg \\ Profesor Facultad de Derecho Universidad Adolfo Ibáñez \\ javier.wilemann@uai.cl
}

\section{Resumen}

En la comprensión identitaria de la dogmática penal, la relevancia que esta le otorga a los discursos relativos a los fines que legitimarían el castigo penal (la "teoría de la pena") es especialmente intensa. El artículo somete a crítica la capacidad de rendimiento de la definición metodológica influenciada por el discurso de la teoría de la pena y de la aplicación directa, en contextos de discusión dogmática, de argumentos de "teoría de la pena". El artículo muestra que la pretensión de identificación de aspectos propios del objeto de la dogmática penal (el "derecho penal") a partir de consideraciones relativas a los fines de su sanción es particularmente débil. Argumentos de concordancia con fines en la interpretación de ciertas instituciones son, en cambio, plausibles en la medida en que la institución en interpretación pueda ser plausiblemente vinculada a esos fines. Ello no arranca, sin embargo, de ninguna consideración relativa a finalidades que sean atribuibles a la "pena en sí".

Palabras clave: Teoría de la pena, dogmática penal, determinación de la pena, retribución, prevención.

\begin{abstract}
Legal theorists tend to identify the distinctive features of criminal law by linking it to the question of the justification of punishment. The paper criticizes the merits of this

\footnotetext{
* Profesor Asociado Facultad de Derecho Universidad Adolfo Ibáñez. Este artículo ha sido desarrollado como parte del proyecto Fondecyt $\mathrm{N}^{\circ} 1170056$ sobre "La conformación del derecho penal entre política y cultura", del cual el autor es investigador responsable. Le agradezco a la Alexander von Humboldt Stiftung por otórgame la beca que hizo posible la realización de esta investigación. La investigación tuvo lugar en el Institut für Strafrecht und Rechtsphilosophie dirigido por el profesor Michael Pawlik en la Albert-Ludwigs Universität Freiburg y en la biblioteca del Max Planck Institut für ausländlische und vergleichende Strafrecht de la misma ciudad, por lo que agradezco la generosidad de estas instituciones. Una versión preliminar de este artículo fue expuesta en el workshop "Cuestiones de filosofía penal” organizado por Enzo Solari en la Facultad de Derecho de la Pontificia Universidad Católica de Valparaíso el día 13 de Enero de 2017. Le agradezco al profesor Solari por su invitación y a todos los participantes por los muy valiosos comentarios recibidos en la oportunidad, los que incluso permitieron reestructurar parte del trabajo.
} 
WILENMANN, Javier. “Contra las prácticas argumentativas de apelación a la "teoría de la pena" en la dogmática penal".

assumption and generally of legal arguments related to such an approach. It shows that the claim that the distinctiveness of criminal law is to be related to the means of punishment is implausible. Certain institutions of positive criminal law can indeed be linked to certain means and ends analyzed when discussing about the traditional theories of punishment. This is, however, only a matter of identifying the ratio legis behind a specific legal configuration and not linked to a general theoretical problem about the general justification of punishment.

Key words: Punishment theory, criminal law, sentencing, retribution, deterrence.

\section{Introducción}

En este artículo, nos interesa someter a crítica el recurso a la invocación de la "teoría de la pena" en la dogmática penal. El artículo participa de una crítica generalizada al modo en que tiende a discutirse en la academia jurídica sobre derecho penal y, en particular, a aquello que tiende a designarse con el nombre de "teoría de la pena". Como parte de este proyecto, el artículo somete a prueba la utilidad de la apelación a la "teoría de la pena" en la dogmática penal. De este modo, en este artículo no se trata de revisar la plausibilidad de ciertas figuras argumentativas también conectadas con la etiqueta "teoría de la pena" relativas a la legitimidad política del castigo penal o al control institucional de decisiones legislativas penales. Esos otros dos aspectos típicamente conectados a la teoría de la pena serán sometidos a crítica en otros dos artículos, ya que se vinculan con discursos académicos distintos (en un caso: filosofía y teoría política; en el otro: derecho y teoría constitucional). Aquí nos interesa revisar la capacidad de rendimiento de la apelación a la "teoría de la pena" en el contexto de prácticas argumentativas que pueden ser identificadas en la dogmática penal; solo ese es su objeto primario de referencia.

El punto de partida de la crítica se encuentra en la constatación de relevancia del pensamiento que a grandes rasgos puede ser denominado "sustantivo" o "moralizante" en la academia jurídica $\mathrm{y}$, de modo paradigmático, en la academia penal. La comprensión académica del derecho penal se ve dominada por la pregunta por sus fundamentos, ante todo legitimatorios, de un modo que no tiene equivalente en las otras disciplinas jurídicas en la actualidad ${ }^{1}$. Tanto en el contexto continental como en el mundo anglosajón, la teoría de la pena es constituida en discurso introductorio en una gran proporción de los textos que

\footnotetext{
${ }^{1}$ Ilustrativo GRECO, Luis, "Verfassungskonformes oder legitimes Strafrecht? Zu den Grenzen einer verfassungsrechtlichen Orientierung der Strafrechtswissenschaft", en: BRUNHÖBER et al (Eds.), Strafrecht und Verfassung, Baden-Baden: Nomos, 2013, pp. 13-36, p. 5: "La ciencia del derecho penal es de acuerdo a su propia comprensión implícita una ciencia de la legitimidad de la pena, no sólo de lege ferenda sino en primera línea de lege laga.” ¿Puede encontrarse una declaración similar en otras disciplinas dogmáticas? Concedido: el derecho constitucional podría ser una excepción, en el que la pregunta por el fundamento del reconocimiento de un poder soberano legítimo sigue jugando un papel relevante. Pero la teoría constitucional no siempre se estructura en torno a ese discurso. En Alemania, la pregunta por la metodología en el acercamiento al estudio del derecho constitucional (y, en general, al derecho del Estado) ha sido dominante. En los Estados Unidos, el rol de la constitución y su metodología de estudio son también preguntas fundamentales que estructuran la comprensión del derecho constitucional. Las ciencias jurídico penales ciertamente no tratan a la pregunta por la legitimidad de la práctica del castigo estatal como la única pregunta fundamental existente - aunque ciertamente no falten exageraciones que así lo hacen -, pero es difícil negar que pragmáticamente ella se ve completamente dominada por esa pregunta.
} 
pretenden tematizar de modo general al derecho penal (manuales, comentarios, etc.) ${ }^{2}$. La teoría de la pena asume así al menos simbólicamente un rol determinante en el estudio del derecho penal, lo que se extiende a lo que puede ser considerado su "ciencia normal" en la tradición continental: la dogmática penal.

Si bien la constatación de la concesión de relevancia al uso de la "teoría de la pena" es relativamente sencillo, la determinación de su contenido y de las razones por las que el fenómeno tiene lugar no es siempre clara. En lo relativo a su contenido: ¿Qué significa legitimar la pena? ¿Explicar las razones morales del reconocimiento del todo de una práctica de castigo? ¿Entregar una explicación política abstracta al hecho de que una autoridad imponga el castigo? ¿Explicar la configuración de las reglas jurídicas que institucionalizan la práctica del castigo punitivo? ¿Lo anterior extendido solo a sus condiciones de imposición? ¿A las condiciones de criminalización legislativa?

En lo relativo a su función: ¿por qué se fijan las ciencias jurídico-penales de un modo tan intenso en la pregunta por la función que cumple la rama del derecho positivo que estudian? ¿Se trata de una preocupación política académica? Que la filosofía política tenga una fijación crítica moral de esta clase con una práctica que se caracteriza por la irrogación de alguna clase de dolor no parece ser problemático -ello explica el interés que la filosofía política tiene en la explicación de la justificación de la pena-, pero no es del mismo modo obvio que una ciencia jurídica se estructure en torno a una pregunta política. ¿Se trata así tal vez de una preocupación propiamente jurídica que determina el modo en que se entiende metodológicamente a sí misma la dogmática penal al realizar su ciencia normal? ¿Se interesa tal vez la ciencia jurídico-penal por controlar la práctica política de manejo del poder punitivo del Estado por medios de discursos jurídicos?

Esta enumeración de preguntas solo pretende dar cuenta de la vaguedad que supone la autoatribución de competencias ligada al discurso típicamente designado como "teoría de la pena" o "teoría de los fines de la pena". Si se constata, sin embargo, que pese a su vaguedad, la "teoría de la pena" constituye una práctica de discusión académica fácilmente reconocible por todos quienes tienen algún acercamiento al estudio del derecho penal y a la que, al menos en apariencia, efectivamente se le asigna una importancia crucial en la comprensión del objeto de estudio, debiera surgir perplejidad. Un discurso conformado a partir de una definición tan amplia e imprecisa de su objeto parece ser un candidato natural a generar problemas de comunicación y de identidad, al punto de que la posibilidad de existencia del discurso es sospechosa. Y, sin embargo, la práctica de discusión "teoría de la pena" existe como un discurso ampliamente practicado y respecto al cual todo sujeto con conocimientos mínimos puede reconocer cuándo está siendo practicado. Esto es: todo penalista (incluso más: todo abogado) entrenado en la universidad contemporánea puede

\footnotetext{
${ }^{2}$ En Alemania, ello ya era constatado por VON WÄCHTER, Carl Georg, Lehrbuch des Römisch - Teutschen Strafrechts, reimpresión, Goldbach: Keip Verlag, 2001, p. 41, en el año 1825 y haciendo referencia a un fenómeno ya verificable 40 años antes. En el mundo anglosajón, la tendencia es identificada y criticada por HUSAK, Douglas, Overcriminalization, Oxford/Nueva York: Oxford University Press, 2008, pp. 4 y ss.; RAMSAY, Peter, "The Responsible Subject as Citizen: Criminal Law, Democracy and the Welfare State", The Modern Law Review, Vol. 69, $\mathrm{N}^{\circ} 1$ (2006), pp. 29-58, pp. 29 y ss.; y KLEINFELD, Joshua, "Reconstructivism: the Place of Criminal Law in Ethical Life", Harvard Law Review, Vol. 129, № 6 (2016), pp. 1485-1565, pp. 1497 y ss.
} 
WILENMANN, Javier. “Contra las prácticas argumentativas de apelación a la "teoría de la pena" en la dogmática penal".

reconocer en una discusión determinada una "discusión sobre teoría de la pena" pese a que no sea claro el objeto de la teoría de la pena como discurso jurídico. La teoría de la pena tiene una identidad especialmente clara pese al hecho de que, vista de cerca, es especialmente vaga.

Por supuesto, la contradicción en cuestión no puede existir: si hay un discurso estable con tanta extensión geográfica y temporal, no puede ser que se trate de un discurso sin identidad. Pero - esa es la tesis- esa estabilidad no es provista por una definición clara de lo que se quiere lograr al practicar la teoría de la pena, sino de la claridad de lo que debe hacerse para practicar teoría de la pena.

La "teoría de la pena" puede, en ese sentido, entenderse como una especie de juego (o, en otra analogía posible, de institución); no en el sentido de que sea algo lúdico y en principio sin relevancia moral, sino en el sentido de que la unidad en cuestión conforma identidad por una definición más o menos clara de reglas que definen el modo en que se practica algo y que luego se actualiza al practicarlo. Este discurso estandarizado exige así entre otras cosas asumir (i) que la pregunta por la legitimidad del acto de irrogación de un mal por un acto pasado es relevante para la práctica política de castigo estatal;(ii) que esa legitimidad solo puede ser explicable ya sea porque es correcto en sí irrogar un mal por una acción especialmente reprochable pasada o porque es necesario para evitar un mal futuro; por lo que (iii) la institución real pena debe ser "retributiva" o "preventiva" en los dos sentidos posibles que el "debe" puede tomar aquí: como exigencia moral efectuada al sistema jurídico (la teoría de la pena, se dice, es en ese sentido "normativa" y no descriptiva) pero también como exigencia de equilibrio reflexivo (la teoría de la pena debe en ese sentido ser mínimamente identificable con la institución jurídica que tematiza) ${ }^{3}$.

Jugar el juego de la teoría de la pena significa, en ese sentido, identificar los argumentos de legitimidad moral y de verosimilitud que hablan en contra o a favor de una lectura preventiva (en sus distintas variantes) o retributiva (en sus distintas variantes) del derecho penal y hacerse cargo en general de los argumentos levantados por la parte contraria. Su claridad de identidad es esa: la tradición milenaria de discusión de la que participa, junto con la enorme influencia que en ella ejerce la imagen de la Ilustración y la tradición del derecho natural racional, establecen reglas de juego tan fácilmente reconocibles que la identidad de la teoría es (contra-intuitivamente) excepcionalmente nítida.

La tesis sobre la que se construye el artículo (y el proyecto del que forma parte) es que la claridad de identidad de la práctica "teoría de la pena" es, al mismo tiempo, causante de falta de rendimiento. En otros términos: la "teoría de la pena" es un discurso que es fácilmente identificable porque es fácil saber cómo se practica, cómo se juega al juego que la conforma, sin que sea del todo claro por qué se juega a ese juego y, por consiguiente, si tiene sentido construir un discurso académico con esa identidad. Todavía más: la naturalidad con la que se juega al juego de la teoría de la pena contribuye a la banalización del discurso teórico (jurídico-filosófico) sobre la teoría de la pena, precisamente porque no es relevante tener conciencia del interés de lo que se está haciendo -y amoldar su

\footnotetext{
${ }^{3}$ Similar RISTROPH, Alice, “Just Violence”, Arizona Law Review, Vol. 56, № 4 (2014), pp. 1017-1063, p. 1039 .
} 
constitución a ese interés- al practicar la "teoría de la pena". La claridad de identidad es, además, fácilmente transferible a los partícipes en la construcción de su propia identidad en el acercamiento al derecho penal ${ }^{4}$ - No es raro, por ello, que buena parte de las discusiones sobre teoría de la pena se transformen en defensas de identidad de bandos: la lucha de escuelas en la academia alemana del Imperio, la polémica en torno a la teoría de la prevención general positiva o la actual discusión entre utilitaristas y moralistas jurídicos (legal moralists) en la academia penal anglosajona muestra esta dimensión ${ }^{5}$.

La confirmación de la hipótesis anterior -la práctica estandarizada de discusión e identificación conocida como "teoría de la pena" no tiene demasiado valor, en el modo en que se practica, para los discursos de legitimación política, de control institucional y de reconstrucción dogmática- exige, por cierto, identificar si las funciones que se le atribuyen a la práctica son valiosas y pueden ser satisfechas en los tres contextos que hemos anticipado. En lo que sigue, se trata de producir ese examen en lo que se refiere específicamente a la dogmática penal.

Para estos efectos, el artículo se divide en tres secciones. La primera sección (1) entrega una pequeña descripción del objeto que es sometido a crítica: solo aquellas "teorías de la pena" ricas en contenido pueden pretender rendimiento dogmático y, por ello, solo ellas son candidatas a ser sometidas a crítica.

Las secciones 2 y 3 contienen, en cambio, la crítica al objeto así identificado. La segunda sección (2) somete a crítica la pretensión de la teoría de la pena de servir como definición metodológica central de la dogmática penal, o al menos de contribuir en gran nivel en determinar su identidad disciplinaria y distinguir a la dogmática del derecho penal de la dogmática del derecho público. Como veremos, la sección (2) intenta mostrar en qué medida la pretensión de distinción por consideraciones sustantivas es un resabio de una comprensión del Estado y del derecho público que fue mayoritariamente abandonada hacia mediados del siglo XIX y cuyo mantenimiento en el ámbito penal no se justifica.

La tercera sección (3), en cambio, se pregunta por el rendimiento de la invocación a la "teoría de la pena" en el contexto del análisis propiamente dogmático, esto es, no en definiciones metodológicas o identitarias generales de la dogmática penal, sino en el análisis particular de instituciones y reglas de derecho positivo penal. Como veremos, la sección 3 muestra que la invocación a la teoría de la pena puede servir o bien para designar

\footnotetext{
${ }^{4}$ Sea dicho de paso: el hecho de que la teoría de la pena tenga tanto poder de identificación académica que sea utilizada no solo para caracterizar teorías, sino también (tal vez: ante todo) para agrupar autores -se es prevencionista o retribucionist -, algo fácilmente reconocible por ejemplo en el famoso artículo de MOORE, Michael, "Justifying Retributivism”, Israel Law Review, Vol. 27, N 1-2 (1993), pp. 15-49, p. 15, cuya pregunta inicial no se refiere a las teorías, sino ¿qué hace a un retribucionista? - es característico de la prestación socio-académica que cumple la teoría de la pena.

${ }^{5}$ Por supuesto, no es en ningún caso extraño en la academia que la identidad de una teoría se transfiera a los partícipes - uno pasa, así, a entenderse a sí mismo como "prevencionista" o "retribucionista" o como "físico cuántico"- y que estos construyan su identidad sobre una teoría determinada. Eso no es problemático, además, si en la construcción y defensa de esa identidad se producen resultados relevantes que trascienden a la defensa, incluyendo al testeo en teorías científicas que vivan bajo el manto de la falsabilidad empírica. Lo que es peculiar y especialmente contra-productivo en la academia penal es, en cambio, el hecho de que muchas discusiones parecen no ser más que defensas de identidad sin otro interés que la defensa de identidad.
} 
WILENMANN, Javier. “Contra las prácticas argumentativas de apelación a la "teoría de la pena" en la dogmática penal".

las pretensiones de ciertas instituciones penales (en cuyo caso, como veremos, la invocación solo cumple un rol de estandarización y simplificación del lenguaje) o bien deforma el modo de argumentación dogmático-penal precisamente cuando no hay representaciones de fines que puedan ser conectadas a los argumentos tradicionales de la teoría de la pena.

\section{Definición del objeto de crítica}

Como anticipamos en la introducción, no nos interesa en este contexto criticar la plausibilidad moral o política de los argumentos que tienden a ser entregados para explicar la legitimidad del castigo penal. Antes, lo que nos interesa es preguntarnos por la capacidad de rendimiento dogmático de la apelación a esa clase de argumentos. La labor de definición del objeto de crítica parece ser, por ello, en principio sencilla: al tratarse de la mera identificación de prácticas especialmente nítidas (todo lector de este texto probablemente cuente con criterios intuitivos de reconocimiento de lo que es una "teoría de la pena") y no, en cambio, de discusión dentro de esa práctica, la nitidez que tiene un juego con reglas tácitas bien definidas debiera hacer más o menos irrelevante la labor de identificación. Así, la mera apelación al potencial apelativo de conceptos tales como "prevención especial", "prevención general ("negativa" y "positiva") y "retribución" debiera ser suficiente para nuestros efectos.

Pese a lo anterior, puede ser útil al menos realizar una distinción entre dos clases de prácticas de apelación a la "teoría de la pena" para definir el objeto de la crítica de este artículo: teorías de la pena ricas en contenido son parte de ese objeto mientras que teorías de la pena vacías no lo son. A continuación explicaremos brevemente la distinción.

Teorías de la pena ricas en contenido son, para nuestros efectos, todas aquellas atribuciones de finalidades pre-definidas (discretas o complejas) a la pena estatal. Las teorías de la pena ricas en contenido necesitan asumir que la pena obtiene su justificación de la producción de un bien moral preciso, sea que este se identifique con la disminución futura de delitos (prevención) o con la realización de alguna idea de justicia (retribución rica en contenido; las denominadas teorías "absolutas" de la pena). Ellas se estructuran, por lo mismo, como aplicaciones de teorías morales (cuando son más bien moralizantes y se desentienden del carácter político de la pena) o de teorías políticas/del Estado. Desde el punto de vista de la dogmática, su aplicación argumentativa significa una transferencia (más o menos limitada) de lógica de razonamiento moral/filosófico-político al pensamiento jurídico.

Teorías de la pena vacías son, en cambio, todas aquellas teorías que renuncian (de algún modo) a atribuirle una finalidad moral o política pre-definida a la pena y que, por ello, delegan la definición de su función en otro nivel. Todas las teorías que funcionan bajo descripción inasiblemente abstractas de fines (en el lenguaje del Imperio Alemán: ¡confirmación de la autoridad del soberano!; en el lenguaje de la actualidad: confirmación de los valores del ordenamiento jurídico) son en ese sentido teorías de la pena vacías: el razonamiento funcional es o bien definido en términos tan abstractos que es inasible o bien lanzado fuera de los márgenes de reflexión jurídica, por lo que no tiene consecuencias en la 


\section{Polít. crim. Vol. 12, № 24 (Diciembre 2017), Art. 4, pp. 754-785. \\ [http://www.politicacriminal.cl/Vol_12/n_24/Vol12N24A4.pdf]}

comprensión del derecho penal. Alguna clase de reflexión de otro tipo es, entonces, aquello que debe servir en las definiciones metodológicas centrales de las ciencias penales.

Teorías de esta clase son así reconocibles tanto en el tratamiento de corte sociologizante de la función de la pena (ella sirve a la afirmación y reproducción de un orden o, lo que es lo mismo, de expectativas de comportamiento de otros) ${ }^{6}$, como en delegaciones al nivel de definiciones incompletas de la autoridad ${ }^{7}$, del Estado ${ }^{8}$, del derecho o del orden normativo (este es en algún sentido la función de la "prevención general positiva", pese a que su mezcla con una apelación a la "prevención" las haga a veces ricas en contenido) $)^{9}$ de la determinación de sus posibles funciones. Como, por definición, las teorías de la pena vacías no pueden producir transferencia de lógicas argumentativas -ellas se caracterizan por negarse a realizar esa transferencia pese a construir, en algún nivel, una dependencia de decisiones de otro nivel ${ }^{10}$, ellas no tienen relevancia dogmática en los términos que nos interesa analizar.

La distinción anterior permite identificar de modo suficientemente preciso el objeto de nuestra crítica: la invocación a teorías de la pena ricas en contenido en definiciones o argumentaciones propiamente dogmáticas. Por cierto, una "precisión" de esta clase se ve todavía aquejada de ambigüedad: puede no parecer claro, por ejemplo, si teorías "expresivas" de la pena o si toda clase de "retribucionismo" entra dentro de nuestro objeto

\footnotetext{
${ }^{6}$ Paradigmático en la discusión reciente JAKOBS, Günther, Strafrecht Allgemeiner Teil, 2. Edición, Berlín/Nueva York: De Gruyter, 1991, 1/20. Pese a tener pretensiones políticas completamente diversas, el mismo vacío de contenido inmediato puede ser encontrado en la teoría marxista sobre la pena y, a partir de ella, en la criminología crítica. En lo primero completamente explícito MARX, Karl "Über die Todestrafe Herrn Cobdens Pamphlet", en: Karl Marx/Friedrich Engels - Werke, Band 8, 3. Edición, Berlín Oriental: Karl Dietz Verlag, 1972, pp. 506-13, pp. 507s. Por referencia a este pasaje de Marx así también MURPHY, Jeffrie, Retribution, Justice and Therapy, Dordrecht: Reidel Publishing Company, 1979, pp. 93 y ss.; PIONTKOWSKI, A.A., Hegels Lehre über Staat und Recht und seine Strafrechtstheorie, editado y traducido por LEKSCHA, John, Berlín Oriental: VEB Deutscher Zentralverlag, 1960, pp. 161 y ss. Entre nosotros así también MAÑALICH, Juan Pablo, "Retribucionismo consecuencialista como programa de ideología punitiva. Una defensa de la teoría de la retribución de Ernst Beling", InDret 2/2015, pp. 19 y ss.

${ }^{7}$ Este era un modo tradicional de estructuración de la teoría de la pena en los pensadores institucionalmente más lúcidos en la academia jurídica del Imperio Alemán. Así MERKEL, Adolf, Vergeltungsidee und Zweckgedanke im Strafrecht, Estrasburgo: Verlag von Karl J. Trübner, 1892, pp. 15 y ss.; JELLINEK, Georg, Die sozialethische Bedeutung von Recht, Unrecht und Strafe, 2. Edición, Berlín: Verlag von O. Häring, 1908, pp. 60 y ss., 114 y ss.; SCHMIDT, Richard, Einführung in die Rechtswissenschaft, 2. Edición, Leipzig: Felix Meiner, 1923, p. 411; SCHMIDT, Richard, Die Aufgaben der Strafrechtspflege, Leipzig: Duncker \& Humblot, 1895, pp. 56 y ss.; BELING, Ernst, Die Vergeltungsidee und ihre Bedeutung für das Strafrecht, reimpresión Aalen: Scientia Verlag, 1978, pp. 36 y ss.

${ }^{8}$ Especialmente elocuente en este sentido nadie menos que BUSTOS Juan, "Kriminalpolitik und Strafrecht", en: HIRSCH, Hans Joachim; KAISER, Günther y MARQUARDT, Helmut (Eds.), Gedächnitsschrift für Hilde Kaufmann, Heidelberg/Múnich/Landsberg/Berlín: De Gruyter, 1986, pp. 69-88, p. 70: "Dentro del sistema social, la pena siempre ha sido y sigue siendo una confirmación del Estado."

9 Especialmente claro, por ejemplo, en GÄRDITZ, Klaus Ferdinand, "Strafbegründung und Demokratieprinzip", Der Staat, Vol. 49 № 3 (2010), pp. 331-67, pp. 357 y ss.; APPEL, Ivo, Verfassung und Strafe, Berlín: Duncker \& Humblot, 1996, pp. 19, 428 y ss., y en la fórmula generalmente utilizada por el BVerfG para describir el sentido de la pena - véase BVerfGE 27, 18 (29) (derecho administrativo sancionatorio) 39, 1 (46) (aborto 1); 45, 187 (asesinato y presidio perpetuo); 88, 1 (257) (aborto 2); 120, 224 (241f.) (incesto).

${ }^{10}$ Véase a este respecto también la sección 2.3 de este artículo.
} 
WILENMANN, Javier. “Contra las prácticas argumentativas de apelación a la "teoría de la pena" en la dogmática penal".

de crítica. Representantes de distintas teorías de la pena pueden sentirse no identificados: después de todo, los argumentos que entregan a favor de una u otra "lectura" del derecho penal no son considerados del todo en este ejercicio. Pero la razón por la que ello no ha sido realizado es precisamente porque, para efectos del argumento, nada de esto importa demasiado: como veremos, dada su estructura, la invocación con pretensiones reales (=no vacías) de influencia argumentativa es problemática; la invocación sin pretensiones reales de influencia argumentativa (= vacía) es irrelevante. Ese es el punto del artículo. Retomando la metáfora del juego: no nos interesa constatar quién juega mejor, de un modo más sofisticado o más efectivo, al juego de la "teoría de la pena" en sí. Nos interesa ver si el tipo de argumentos que se invocan al practicar ese juego pueden o deben jugar algún rol en la argumentación propiamente dogmática en las ciencias penales. Nuestros criterios rústicos y amplios de identificación del objeto de la crítica son, por ello, no solo suficientes, sino necesarios: criterios más precisos producirían un estrechamiento innecesario de la crítica que se trata de producir en las próximas secciones.

\section{La insuficiencia de la teoría de la pena como discurso con rendimiento meta- dogmático}

Como hemos visto, el primer rendimiento que puede atribuírsele a la "teoría de la pena" en la dogmática penal puede ser denominado "meta-dogmático": la relevancia que tradicionalmente le ha entregado la dogmática jurídica a la teoría de la pena ha contribuido a mantener una identidad metodológica determinada en relación con las otras ciencias jurídicas. Esto puede ser explicado de modo relativamente sencillo como aplicación de una idea más general.

Como cuestión de teoría y sociología de las ciencias, la determinación (consciente o inconsciente) de un método asociado a una disciplina es una determinación de su identidad. A contrario, ello implica que el reconocimiento de una disciplina científica independiente presupone la generación de una identidad independiente y ello significa al menos una definición metodológica que en un ámbito determinado sea distinguible de sus alternativas. Socio-académicamente observado, no es difícil reconocer que la "ciencia del derecho penal" es -con particular nitidez en la tradición continental- una disciplina independiente. En parte, aquello que le ha permitido mantener su identidad en el largo tiempo de conformación de las distintas disciplinas jurídicas contemporáneas ha sido su propia fijación (sustantiva) metodológica. Como la pena es vista como un fenómeno jurídico único que requiere de una evaluación legitimatoria diferenciada, el vínculo con esa pregunta legitimatoria ha sido históricamente construido como criterio de distinción de la dogmática penal $^{11}$. En otras palabras: la teoría de la pena ha contribuido a "asegurar la independencia de la dogmática penal", a configurar aquello que es percibido como distintivo del derecho penal y, con ello, a la defensa de la propia identidad de los actores que, en el ámbito jurídico, practican el juego de la teoría pena. En este apartado se trata de revisar si esta prestación de auto-identificación y definición metodológica puede ser consistentemente

\footnotetext{
${ }^{11}$ Véase, con ulteriores referencias, KASPAR, Johannes, Verhältnismäßigkeit und Grundrechtsschutz im Präventionsstrafrecht, Baden-Baden: Nomos, 2014, p. 38, por referencia a la resistencia al discurso constitucional.
} 
producida por la teoría de la pena, esto es, si ella debiera tener un rol "meta-dogmático" del todo.

\subsection{La teoría de la pena y lo propio del derecho penal}

Si la teoría de la pena tiene por pretensión definir la metodología de la ciencia del derecho penal y, a partir de ello, definir el modo en que el derecho penal mismo es entendido, ello debe implicar que posee características que la diferencian del resto del derecho público. Esto es: en la orientación sustantiva y relativa a fines que caracteriza a la teoría de la pena debe haber algo que permita tratar al derecho penal de un modo independiente del resto del derecho público que justifique la separación disciplinaria fuerte que caracteriza a ambas disciplinas. Si esa diferenciación se justifica en el tipo de reflexiones que caracterizan a la teoría de la pena, entonces es natural que la orientación disciplinaria propia del derecho penal siga las definiciones metodológicas que pueda proveer la teoría de la pena. Al revés: si la teoría de la pena cumple en los hechos la prestación de permitir mantener una diferenciación disciplinaria fuerte entre derecho público y derecho penal $-\mathrm{y}$, en los hechos, lo pretende- entonces una crítica como la que aquí ofrecemos implicaría, de ser exitosa, poner en peligro la diferenciación metodológica fuerte entre derecho penal y derecho público en general.

Antes de responder a esta objeción mostrando el modo en que el desprendimiento de la teoría de la pena debiera permitir ver las verdaderas particularidades del derecho penal ciertamente sustantivas pero no relativas a las funciones que cumple el derecho penal-, es posible responder a este argumento preguntándose si esta prestación de identificación efectivamente realizada por la teoría de la pena debiera tener lugar, esto es, si pensada hasta el final, la teoría de la pena permite efectivamente diferenciar al derecho penal de otras formas de derecho y, en especial, de otras formas de derecho público sancionador. Quienquiera que asuma un mínimo de consistencia en la academia debe responder que sí, porque lo ha hecho: si la prestación ha sido entregada, debe haber algo en el medio -la teoría de la pena- que permita que ella se realice. Nuestra crítica necesita asumir, por ello, que el problema en la pretensión meta-dogmática de la teoría de la pena no es la falta de rendimiento en sí, sino más bien si el modo en que se produce ese rendimiento puede ser justificado.

La tesis a este respecto es sencilla: la fijación sustantiva de las ciencias penales no se explica por particularidades del derecho penal (en el sentido de que sea inherentemente "más sustantivo", "más necesitado de reflexión moral", etc.) respecto al derecho público en general (en el cual el problema de la dominación política se juega de modo mucho más extenso), sino simplemente al hecho de que el derecho penal no ha seguido al resto del derecho público en su evolución histórico-dogmática. Esto es: la dogmática general del derecho público (la dogmática del "derecho del Estado" en la calificación tradicional alemana) abandonó, en los hechos, en el curso de la segunda mitad del siglo XIX la metodología funcional sustantivizada que sigue caracterizando (al menos en apariencia) al derecho penal. Este abandono se deja reconocer en la marginalización de la (hasta entonces crucial) teoría de los fines del Estado, de la que la teoría de (los fines de) la pena no era 
WILENMANN, Javier. "Contra las prácticas argumentativas de apelación a la "teoría de la pena" en la dogmática penal".

más que una aplicación ${ }^{12}$. Como la teoría de la pena rica en contenido depende de la teoría de los fines del Estado, la teoría de la pena necesita en el fondo reclamar continuidad ( $\mathrm{y}$ no ruptura!) entre dogmática general del derecho público (derecho del Estado) y dogmática penal $^{13}$.

El reclamo de continuidad entre derecho penal y el resto del derecho público se nota con particular nitidez, de hecho, si uno asume (como Feuerbach) que la pregunta por la justificación de la pena no es más que la pregunta sobre cómo la pena se orienta a la satisfacción del fin que justifica al Estado (en el caso de Feuerbach: mantenimiento del estado civil kantiano). Estas dificultades son claramente visibles en el clásico trabajo de Robert von Mohl: al intentar trazar diferencias desde el punto de vista de los fines del Estado entre derecho público y derecho penal, la única conclusión posible es que el derecho penal no se diferencia del resto del derecho administrativo. El derecho penal pertenecería a las instituciones que pretenden cumplir funciones de aseguramiento del estado jurídico ${ }^{14}$ pero ello no sería en ningún caso exclusivo a este. A lo más, sería posible distinguir entre aseguramiento por medio de represión (derecho penal) y aseguramiento por medio de verdadera prevención (derecho de policía, pero también participación del Estado en la educación $)^{15}$. Con ello, precisamente si uno entiende el derecho penal à la Feuerbach -y la propia comprensión de Mohl es cercana a éste-, entonces parece ser que la no diferenciación metodológica entre derecho penal y derecho administrativo es la

\footnotetext{
${ }^{12}$ La dependencia de la teoría de (los fines de) la pena de una teoría del Estado que asume fines fijos de este se deja reconocer fácilmente en toda la tradición del derecho natural racional y en su adaptación en la obra de Feuerbach, la que resultó decisiva en la estructuración temprana de la dogmática penal. Véase FEUERBACH, Paul Johann Anselm, Lehrbuch des gemeinen in Deutschland gültigen peinlichen Rechts, reimpresión, Aalen: Scientia Verlag, 1986, pp. 36 y ss.; EL MISMO, Revision der Grundsätze und Grundbegriff des positiven peinlichen Rechts, reimpresión, Aalen: Scientia Verlag, 1966, pp. 38 y ss. Más allá del caso de Feuerbach, en la literatura del siglo XIX, especialmente nítidos en la adopción de una estructura de argumentación de esta clase VON GROLMAN, Karl, Grundsätze der Criminalrechtswissenschaft, reimpresión, Goldbach: Keip Verlag, 1996, pp. 4 y ss.; VON MOHL, Robert, Die Polizei-Wissenschaft nach den Grundsätzen des Rechtsstaates. Dritter Band: System der Präventiv-Justiz, 3. Edición, Tubinga: Verlag der H. Laupp'schen Buchhandlung, 1866, pp. 9 y ss.; BAUER, Anton, Lehrbuch des Strafrechts, reimpresión, Goldbach: Keip Verlag, 1996, pp. 25 y ss.; EL MISMO, Die Warnungstheorie, reimpresión, Goldbach: Keip Verlag, 1996, pp. 1 y ss.

${ }^{13}$ Por supuesto: más allá de toda cuestión teórica, siempre será posible distinguir entre derecho penal y el resto de las ramas del derecho público por cuestiones históricas. Así, a causa del origen pre-estatal y preinstitucional del derecho penal, el derecho penal se ve determinado en una medida mucho mayor por categorías provenientes del derecho romano y el derecho canónico. También hay razones históricoinstitucionales que explican la diferenciación de ambas disciplinas: las prácticas punitivas se desarrollaron tempranamente con cierta independencia del poder del gobierno a través del recurso a la juridificación y judicialización. Esto se expresa ante todo en la representación ilustrada de que el poder gubernamental no puede tener injerencia determinante en la administración de justicia penal. El derecho administrativo tiene un origen exactamente opuesto, a saber, no la resistencia a la puesta a disposición del poder de reglas, sino la resistencia del poder a dejarse juridificar: la soberanía exigiría que la administración no se encuentre sujeta a reglas. En este SENTIDO JELLINEK, Georg, Allgemeine Staatslehre, 3. Edición, Darmstadt: Wissenschaftliche Buchgesellschaft, 1960, p. 388.; STOLLEIS, Michael, "Entwicklungsstufen der Verwaltungsrechtswissenschaft", en: HOFFMAN-RIEM, Wolfgang; SCHMIDT-AßMANN, Eberhard; VOßKUHLE, Andreas (Eds.), Grundlagen des Verwaltungsrechts. Band I, Múnich: Beck, 2006, pp. 63-119, Nm. 21 y ss.

${ }^{14}$ VON MOHL, Die Polizei-Wissenschaft, cit. nota ${ }^{\circ} 12$, pp. 1 y ss., 12 y s. Similar SCHMIDT, Einführung in die Rechtswissenschaft, cit. nota $\mathrm{n}^{\circ} 7, \mathrm{pp} .409$ y ss.

${ }^{15}$ VON MOHL, Die Polizei-Wissenschaft, cit. nota n ${ }^{\circ} 12$, p. 5.
} 
Polít. crim. Vol. 12, No 24 (Diciembre 2017), Art. 4, pp. 754-785.

[http://www.politicacriminal.cl/Vol_12/n_24/Vol12N24A4.pdf]

consecuencia ${ }^{16}$. Hoy en día incluso esta vía está, por lo demás, vedada: el derecho administrativo también puede tener una orientación represiva, pese a que la imposición de sanciones administrativas no requiere tener una orientación puramente retrospectiva como en el caso del derecho penal -ello, nuevamente, diferencia a ambos ámbitos como medios puestos a satisfacción de fines indefinidos. Por ello, si la diferenciación del derecho penal respecto del resto del derecho público ha tenido lugar de la mano del mantenimiento de una identidad metodológica sustantivizada, ello ha sucedido porque el derecho penal no ha seguido la evolución del derecho público, pero nada en el argumento se orienta a explicar por qué ello no debió ser así.

De lo anterior puede extraerse una consecuencia, la que será confirmada más adelante: si no hay diferencia en relación a los fines que deben ser cumplidos por las distintas sub-ramas del derecho público, entonces las diferencias que puedan establecerse entre el derecho penal y el resto del derecho público no dicen relación con los fines que pueden ser perseguidos por medio del uso de uno u otro sistema normativo. A causa de lo anterior, el reclamo de identidad propia de las ciencias penales en base a consideraciones funcionales o, en general, en base a reflexiones de justicia sustantiva no puede ser convincente. Esto es, por supuesto, trivialmente verdadero desde el momento en que también se legisla en el ámbito del derecho administrativo, e incluso en el ámbito del derecho privado, con pretensiones preventivas, simbólicas, expresivas, etc. Pero ello no quiere decir que no existan diferencias entre estos sistemas normativos: se trata, por cierto, de sistemas de reglas con contenidos diferenciables. Como el legislador puede usar con relativa discreción uno u otro sistema normativo para satisfacer los fines que persiga, la diferenciación no puede depender de pre-atribución de fines a cada sub-sistema, sino más bien en que cada sistema tiene ámbitos de idoneidad potencial distintos relativos precisamente al contenido de cada sistema.

Lo anterior implica que las particularidades del derecho penal y sobre las que puede construirse su metodología propia no se encuentran en el ámbito de los fines que persigue: sistemáticamente la discusión en cuestión es propia del ámbito de la política y la competencia para su decisión es legislativa sin que la identidad del derecho penal afecte en nada las decisiones potenciales, salvo en que su racionalidad se ve condicionada por la idoneidad potencial del subsistema en cuestión ${ }^{17}$. Con ello, sus particularidades se encuentran precisamente en aquello que distingue al derecho penal -presentado aquí bajo la lógica sencilla de la racionalidad instrumental- como medio (ciertamente disponible, pero con una identidad pre-determinada por su existencia).

\footnotetext{
${ }^{16}$ VON MOHL, Die Polizei-Wissenschaft, cit. nota ${ }^{\circ} 12$, p. 16. Véase también pp. 45 y ss.

${ }^{17}$ Similar FARMER, Lindsay, "Criminal Law as an Institution", en: DUFF et al (Eds.), Criminalization. The Political Morality of the Criminal Law, Oxford/Nueva York: Oxford University Press, 2014, pp. 80-100, pp. 81 y s., 98 y ss. También MACCORMICK, Neil, Institutions of Law: an Essay in Legal Theory, Oxford/Nueva York: Oxford University Press, 2007, pp. 207 y ss.
} 
WILENMANN, Javier. “Contra las prácticas argumentativas de apelación a la "teoría de la pena" en la dogmática penal".

\subsection{El ejemplo del legislador astuto como demostración de las particularidades instrumentales del derecho penal}

El punto expuesto anteriormente puede ser graficado por medio de un experimento hipotético, al que denominaremos "el ejemplo del legislador astuto". El objetivo de la reflexión en torno a este experimento hipotético es doble: en primer lugar, mostrar que, desde el punto de vista de los fines que se le atribuyen a la legislación, el derecho penal no tiene particularidades; $y$, en segundo lugar, reflexionar sobre aquello que es efectivamente propio del derecho penal y que, por ello, permite justificadamente determinar la identidad metodológica de las ciencias jurídico-penales.

Asumamos que nos encontramos en un sistema jurídico de intenso control judicial, en el que los jueces supremos poseen o se atribuyen potestades de control judicial de constitucionalidad más o menos relevantes y que ellas tienden a concentrarse en el ámbito del derecho penal -otras formas de sanción estatal son apenas controladas y, en cualquier caso, los estándares son mucho más laxos. Aburrido del intenso control de su legislación penal, el legislador decide tomar un camino brutalmente astuto: re-configurar todo el derecho penal como puro "derecho administrativo sancionador general", ampliando al mismo tiempo el ámbito de conductas sancionables. Ello le permite establecer, o así al menos piensan los asesores de la mayoría parlamentaria, procedimientos más eficaces, un ámbito de acción mayor y mayores diferenciaciones en las condiciones de aplicación de las consecuencias jurídicas sancionatorias. Aquí se plantean dos preguntas distintas: ¿qué puede hacer el tribunal (asumiendo que sea consistente con sus propias premisas) frente a esta maniobra? ¿Y qué pierde el legislador al llevar a cabo su astuta maniobra?

La primera pregunta depende, por cierto, de la regulación constitucional particular. Pero asumamos que las típicas regulaciones constitucionales relativas al derecho penal se encuentran presentes: principio de legalidad, exigencias de culpabilidad sustantiva y procesal (principio de inocencia), debido proceso con algunas exigencias relativas a la detención y sobre todo una garantía de judicialidad de la aplicación de la pena. Para determinar si estas garantías son aplicables, o no, a su nuevo derecho administrativo sancionador general, el tribunal debe revisar si aquello que hizo el legislador es derecho penal, ya que las garantías en cuestión son aplicables a la legislación penal ${ }^{18}$. Determinar qué es derecho penal para estos efectos es, por supuesto, problemático, porque la pena es un instrumento en principio constituido y definido legalmente ${ }^{19}$, con lo que aplicar del todo la

\footnotetext{
${ }^{18}$ Esta es la pregunta central a la que se enfrentó el Tribunal Constitucional Alemán (BVerfGE 22, 49; 38, $347 ; 71,108)$ a propósito de la conversión del antiguo derecho penal administrativo en "derecho infraccional" directamente aplicado por el ejecutivo y que fue, a su vez, revisado por la Corte Europea de Derechos Humanos (Oztürk v. Germany). En ambos casos, la conclusión fue que el concepto constitucional (o de derechos humanos) de pena se aplicaba a este nuevo derecho pero solo respecto de ciertas (indeterminadas) garantías. A este respecto véase TIEDEMANN, Klaus, Verfassungsrecht und Strafrecht, Heidelberg: C.F. Müller, 1991, pp. 15 y ss.

${ }^{19}$ Sobre las aporías que tradicionalmente se han identificado en la determinación del ámbito del derecho penal por su dependencia de definiciones institucionales véase VOLK, Klaus, "Alles Strafe, oder was? - Zum Begriff der Strafe", e:n JUNG, Heike; LUXENBURGER, Bernd; WAHLE, Eberhard (Eds.), Festschrift für Egon Müller, Baden-Baden: Nomos, 2008, pp. 709-15, pp. 709 y ss. En el Reino Unido, la cuestión de la definición de la pena ha sido objeto de una discusión que tiene algún status de clásica, sobre si solo las tradicionales "definiciones procedimentales" de la pena y del delito son conceptualmente posibles. El locus
} 
regulación constitucional fuera de los casos denominados por el propio legislador como legislación penal requiere necesariamente establecer un concepto para estos efectos preinstitucional de pena ${ }^{20}$.

Supongamos, sin embargo, que el tribunal supremo es prudente y maneja un concepto prelegal limitado de pena: el derecho penal y sus garantías son vistos como necesariamente aplicables solo allí donde sean aplicables ciertas consecuencias jurídicas. Las constituciones suelen de hecho vincular el derecho penal a la privación de libertad (cautelar y/o sancionatoria). El tribunal debiera, entonces, asumir que puede controlar por completo la maniobra astuta del legislador si entre las consecuencias jurídicas contempladas en este "derecho administrativo sancionador general" se encuentra la pena privativa de libertad (u otras penas restrictivas de libertad o la pena de muerte). En el resto de los casos, en cambio, al menos no todas las limitaciones serían aplicables. La pretensión de aplicación de ciertas sanciones es, por ello, algo que distingue en primer lugar al derecho penal, pero parece por ahora ser una característica más bien limitada y fácilmente eludible por el legislador astuto. Si el legislador hizo uso de sanciones privativas de libertad en su derecho administrativo sancionatorio general, un tribunal constitucional seguramente declararía que se saltó tramposamente las limitaciones impuestas por la constitución respecto al derecho penal y evaluaría la legislación en cuestión a la luz de las decisiones institucionales que definen al derecho penal, por lo que por definición debiera declarar la maniobra total o al menos parcialmente inconstitucional.

El hallazgo anterior permite contar con una primera aproximación a lo que caracteriza al derecho penal: es un modo de regulación de la posibilidad de imponer sanciones que implica la asunción de ciertas restricciones (ante todo procedimentales, pero, como veremos, también sustantivas) cuya satisfacción permite el uso de mecanismos de otro modo vedados (ante todo: cárcel). El derecho penal y sus limitaciones constitucionales se revelan aquí en su dimensión (ya exaltada por Franz von Liszt) de carta magna del ciudadano frente a ciertos tratos del Estado.

classicus de una conclusión de esta clase es WILLIAMS, Glanville "The Definition of Crime", Current Legal Problems, Vol. 8, N 1 (1955), pp. 107-130. Al respecto véase también HORDER, Jeremy, "Bureaucratic 'Criminal' Law" en: DUFF et al (Eds.), Criminalization. The Political Morality of the Criminal Law, Oxford/Nueva York: Oxford University Press, 2014, pp. 103-131, pp. 103 y ss.; ORMEROD, David, Smith and Hogan's Criminal Law, 13. Edición, Oxford/NuevaYork: Oxford University Press, 2011, pp. 12 y ss.; LAMOND, Grant, “What is a Crime?”, Oxford Journal of Legal Studies, Vol. 27, № 4 (2009), pp. 609-632.

${ }^{20}$ Este es el problema dogmático-constitucional de las denominadas "garantías institucionales" (mejor: garantía de institución): el derecho constitucional aseguraría el mantenimiento de instituciones que provienen de regulación legal sin presuponer, sin embargo, que no puedan ser alteradas en su contenido interno. La institución debe permanecer así a grandes rasgos reconocibles, pero el legislador tiene margen de regulación dentro de ella. Respecto de la pena y de la administración de justicia penal el lenguaje utilizado tiende a ser, en cambio, más impreciso: el concepto específico de garantía institucional, incluso el concepto más amplio de garantía de establecimiento de instituciones (Einrichtigunsgarantie), no tiende a ser aplicado aquí. La razón es sencilla: el derecho constitucional es visto como mirando con sospecha a la pena, por lo que no la garantizaría, sino que la regularía. En qué medida esto es compatible con el discurso constitucional proveniente precisamente de Alemania (aborto I: BVerfGE 39, 1), en el sentido de que la constitución (y recientemente de modo mucho más fuerte: el derecho internacional de los derechos humanos) establece obligaciones de protección que incluyen obligaciones de punición, puede quedar abierto. Solo es importante reconocer que el discurso de las obligaciones de punición implica tratar a las disposiciones constitucionales sobre la pena como "garantías de institución". 
WILENMANN, Javier. "Contra las prácticas argumentativas de apelación a la "teoría de la pena" en la dogmática penal".

Asumamos que el legislador astuto anticipó esto y, para evitar que el tribunal supremo pudiera fácilmente echar abajo su trabajo, no hizo uso de penas privativas o restrictivas de libertad sino de consecuencias generalmente aceptadas en el ámbito del derecho administrativo -ante todo de multas. Si este es el caso $-\mathrm{y}$ a menos que se considere que el Estado tiene deberes de punición- entonces el tribunal supremo debiera asumir que su decisión no puede ser revisada. ¿Qué perdió el legislador con su maniobra astuta? Esta es la pregunta que nos interesa responder, porque permite identificar qué particularidad como instrumento político tiene el derecho penal y, con ello, qué es lo propio de este, más allá de la obviedad de que tiene identidad propia porque se trata de un subsistema normativo.

Una primera respuesta probablemente sea relativa a fines: ¡perdió capacidad de prevención! Pero aunque esto sea cierto -y eso es una cuestión empírica-, no hay nada que todavía distinga al derecho penal del derecho administrativo sancionatorio general que vaya más allá del modo de cumplimiento de una misma función: ambos tienden o pretenden tender a la prevención. En ambos casos se trata de subsistemas cuya única función es reaccionar frente a transgresiones pasadas de reglas $y$, en ese sentido, en cualquier caso tienden directamente a la reafirmación de autoridad. La afirmación: el derecho administrativo sancionatorio general carece de capacidad preventiva no es, en ese sentido, una afirmación relativa a su función pretendida -es decir, no se refiere al qué; aquí no hay particularidades del derecho penal-, sino a que ciertas finalidades tal vez solo puedan ser satisfechas con ciertas consecuencias especialmente drásticas (p. ej.: cárcel), con lo que volvemos al punto anterior. El derecho penal sería el derecho represivo con pretensiones preventivas más duras y, por preocupación política, sujeto a restricciones más intensas. Si este es el caso, no es aquello que tiende a ser denominado "teoría de la pena" lo que puede justificar una orientación metodológica independiente del derecho penal.

¿Pero el legislador astuto no perdió más que cierta capacidad preventiva al eliminar el derecho penal? Recuérdese: el legislador no solo, en el fondo, abolió la cárcel para saltarse los controles impuestos por el tribunal supremo, sino que lo hizo con el objetivo de tener procedimientos más eficaces y una regulación de las condiciones de imposición de la sanción más flexibles tanto sustantiva como procesalmente. Sustantivamente considerado ello implica, en el fondo, saltarse el denominado "principio de culpabilidad", que no es más que la conjunción de las condiciones generales de imposición del castigo construidas a partir de una idea: responsabilidad, constituida bajo un ideal político de igualdad racional, por infracción normativa. Ello implica, al mismo tiempo, que el derecho penal une nuestra representación común de la responsabilidad en base a igualdad normativa racional con la imposición de sanciones retrospectivamente orientadas $y$, ante todo, con la privación de libertad: solo puede perder la libertad quien es responsable bajo el modelo de la responsabilidad racionalista igualitaria, pero al mismo tiempo toda pérdida de libertad se deja conectar con lo que significa la responsabilidad bajo ese modelo ${ }^{21}$.

\footnotetext{
${ }^{21}$ Cercanos, aunque a partir de categorías que ubican como de teoría de la pena, VON HIRSCH, Andrew; y JAREBORG, Nils, Strafmaß und Strafgerechtigkeit, Bonn: Forum Verlag Godesberg, 1991, pp. 9 y ss.: ejemplos de esta clase mostrarían que el derecho penal se distingue en su capacidad expresiva de reproche. Pero lo crucial no es solo que haya expresión de reproche - de hecho, también la hay en el derecho administrativo sancionatorio- sino que ese reproche se construya sobre representaciones generales de responsabilidad en base a igualdad normativa. El derecho penal mantiene vivas, justamente a causa de su carácter cultural de derecho central, esas representaciones.
} 


\section{Polít. crim. Vol. 12, № 24 (Diciembre 2017), Art. 4, pp. 754-785. [http://www.politicacriminal.cl/Vol_12/n_24/Vol12N24A4.pdf]}

No necesitamos, en este punto, contar con una comprensión depurada de qué significa ni qué justifica esta unión. Solo basta con constatar que, asumida la condición política contingente del derecho penal, se abre una comprensión sobre lo que le es propio y lo que se pierde sin él y, con ello, una justificación verosímil (y correctamente sustantiva) sobre lo que distingue al derecho penal como objeto de estudio y, por ello, a las ciencias penales como metodología: el derecho penal confirma (por su propia tendencia a mostrar su necesidad) un modo de comprendernos recíprocamente presente en la cultura y que tiene valor político confirmado por la idea misma de democracia, a saber, la atribución de igualdad racional ${ }^{22}$. El derecho penal confirma y desarrolla las categorías de responsabilidad que surgen de ello, con lo que también desde el punto de vista de la cultura tendemos a reproducir modos de trato recíprocos en atribuciones de responsabilidad similares a aquellos que se encuentran presentes en el derecho penal. La acción política puede, sin embargo, alterar estructuras de la cultura y nuestras ideas de responsabilidad ciertamente no son herméticas a ello. No es necesario pensar en casos extremos como la idea de atribución de responsabilidad sin culpabilidad en el derecho penal pre-moderno (ejemplo: el hijo del herético) para dar cuenta del punto, sino que basta con revisar el modo en que nuestra comprensión de responsabilidad ha cambiado con las alteraciones en la edad de imputación penal ${ }^{23}$.

Ello permite ver qué es lo que se juega en la defensa del derecho penal como modo de funcionamiento del derecho preventivo reactivo central: no es la pérdida de una función estatal en sí -prevención es algo que se extiende por toda la actividad estatal e incluso la prevención por medio de represión tiene también lugar por otros instrumentos legales-, sino el mantenimiento de un ideal político unido a una idea de responsabilidad que hasta el día de hoy conserva presencia en el mundo pre-institucional de la cultura. El hecho de que la Parte General del derecho penal asuma la lógica aparentemente no política (pero en realidad: completamente artificial) de la responsabilidad por merecimiento no es, de este modo, casual $^{24}$, sino que implica simplemente la consideración de que la libertad que

\footnotetext{
${ }^{22}$ Esto acerca al derecho penal a la democracia: ambos son solo justificables en base a una decisión política por mantener una idea de igualdad normativa abstracta. El derecho penal lo hace por la vía de hacer igualmente responsable a todo sujeto, con casi completa independencia de sus condiciones de base, por los hechos que ha realizado. La democracia lo hace por la vía de declarar la igualdad de peso de cada opinión como principio constitutivo. Esta idea ha sido explotada por MÖLLERS, Christoph, Gewaltengliederung, Tubinga, Mohr Siebeck, 2005, pp. 35-37.

${ }^{23} \mathrm{Al}$ respecto fundamental GÜNTHER, Klaus, Schuld und kommunikative Freiheit, Fráncfort del Meno: Vittorio Klostermann, 2005, pp. 245 y ss.; EL MISMO, "Die Zuschreibung strafrechtlicher Verantwortlichkeit auf der Grundlage des Verstehens", en: LÜDERSSEN, Klaus (Ed.), Aufgeklärte Kriminalpolitik oder Kampf gegen das Böse?, Baden-Baden: Nomos, 1998, pp. 319-349, pp. 328 y ss.; KINDHÄUSER, Urs, "Rechtstreue als Schuldkategorie", Zeitschrift für die internationale Strafrechtsdogmatik, 1995, pp. 701-733, pp. 718 y ss.; EL MISMO, "Strafrechtliche Schuld im demokratischen Rechtsstaat", en: HERZOG, Felix; y NEUMANN, Ulfried (Eds.), Festschrift für Winfried Hassemer zum 70. Geburtstag, Heidelberg: Carl Heymanns, 2010, pp. 761-774, pp. 770 y ss.

${ }^{24}$ La función de la Parte General de limitar el ejercicio de coacción estatal, al disponer que un adulto relativamente sano no puede ser tratado de otro modo que como individuo racional y auto-determinado también ha sido enfatizada por BRUDNER, Alan, Punishment and Freedom, Oxford/Nueva York: Oxford University Press, 2009, ix. Desde el punto de vista del derecho público en general véase BÖCKENFÖRDE, Ernst-Wolfgang, Staat, Verfassung, Demokratie, 2. Edición, Fráncfort del Meno: Suhrkamp, 1992, pp. 15 y ss.: el derecho penal tendría a veces un carácter político, mientras que el derecho público no penal sería siempre político. La frase de Böckenförde tiene un significado preciso: el derecho penal no debiera tener más
} 
WILENMANN, Javier. "Contra las prácticas argumentativas de apelación a la "teoría de la pena" en la dogmática penal".

pretende ser garantizada y posibilitada por el sistema estatal incluye (pero no necesita reducirse) a la libertad abstracta presupuesta por esta concepción de la responsabilidad. ${ }^{25}$ La defensa de un derecho de "defensa social" que tenga la forma del derecho penal (principio de culpabilidad incluyendo principio del hecho) debe entenderse, entonces, no como un hecho metafísico o como una exigencia de optimización preventiva, sino como defensa política de un modo de comprender nuestra libertad y, a partir de ella, nuestra concepción de la responsabilidad $^{26}$. En contraste con el retribucionismo tradicional, la investigación sobre lo propio del derecho penal como derecho de la culpabilidad no debe considerarse una investigación sobre hechos pre-políticos o cuestiones necesarias a la moral individual, sino como determinación de las condiciones de realidad de un derecho que sea compatible con la idea de libertad que subyace a las categorías hegelianas de derecho abstracto y moralidad ${ }^{27}$.

Esto no quiere decir, sin embargo, que las ideas políticas en cuestión sean incontestables. El derecho penal es ciertamente un modo de control social con especial influencia en el mundo de la cultura, con lo que puede servir para confirmar modos de atribución de responsabilidad y de comprensión mutua de tendencia racional o igualitaria. Pero una comunidad animada por una comprensión centrada en la maleabilidad humana en su dependencia del ambiente puede renunciar parcialmente a esta idea y orientarse de otro modo. Aquí también puede establecerse una contraposición clara entre las escuelas "clásica" y "moderna" durante el Imperio alemán ${ }^{28}$ y entre partidarios de un derecho penal construido sobre sentencias indeterminadas dominante en los Estados Unidos hasta los 70 y un derecho penal orientado a "just deserts" (y, en su versión conservadora, a "law and order") que ha sido dominante desde entonces ${ }^{29}$. Lo único importante es lo siguiente: esta es una confrontación política y no algo inmanente al derecho penal.

que las implicancias políticas que le son necesarias (confirmación del orden estatal y confirmación de una idea política de responsabilidad), mientras que el derecho público general se orienta siempre a la solución de problemas políticos contingentes. Solo el derecho penal "regulatorio" (de actividades económicas o en el establecimiento y resguardo de instituciones) tendría adicionalmente este carácter.

${ }^{25}$ Así también en tendencia BRUDNER, Punishment, cit. nota ${ }^{\circ} 24$, p. ix.

${ }^{26}$ Así describía acertadamente SCHMIDT, Die Aufgaben der Strafrechtspflege, cit. nota n ${ }^{\circ}$, pp. 7 y ss., la pretensión política de la escuela clásica (o "tradicional") en la denominada lucha de escuelas durante el Imperio Alemán. La crítica a este respecto no puede ser, como tendía a ser imputado por la "escuela moderna", que la escuela clásica defendiera una comprensión idealista o pre-moderna del ser humano plagada de asunciones metafísicas - eso era obviamente solo retórica política escondida bajo la (evidentemente falsa) diferenciación de teorías absolutas y relativas de la pena. La pregunta es más bien otra, a saber, si la defensa del ideal normativo de igualdad abstracta merece o no reconocimiento.

${ }^{27}$ Así también BRUDNER, Punishment, cit. nota ${ }^{\circ} 24$, pp. 15 y ss.

${ }^{28}$ Esta orientación política a la imposición de un Estado general constituido sobre atribuciones de racionalidad y dignidad o sobre pretensiones de distribución racional de bienestar, podía ser ya identificada como primaria en esta disputa por MERKEL, Vergeltungsidee, cit. nota $\mathrm{n}^{\circ} 7$, pp. 42 y ss.

29 Acertado TONRY, Michael, "Obsolescence and Immanence in Penal Theory and Policy Author", Columbia Law Review Vol. 105, N 4 (2005), pp. 1233-1275, pp. 1241 y ss. Su descripción de la tendencia a deformar las ideas contrarias es también acertada: mientras, contra la comprensión propia del otro lado, un lado ignora por completo la orientación democratizante del just deserts y pretende presentarlo como puro conservadurismo vengativo, la estructuración anterior del derecho penal tiende a ser presentada como pura discreción irracional por los partidarios del just deserts, sin dar cuenta del trasfondo de la ideología del Estado de bienestar que le subyacía. 
Polít. crim. Vol. 12, No 24 (Diciembre 2017), Art. 4, pp. 754-785.

[http://www.politicacriminal.cl/Vol_12/n_24/Vol12N24A4.pdf]

\subsection{Sobre la conexión entre definiciones de fines y configuración institucional}

Pese a que no estructuren su discurso del mismo modo en que lo hemos realizado nosotros, es usual encontrar en la literatura contemporánea teorías de la pena que asumen que lo propio del derecho penal (esto es, la definición metodológica de la observación dogmática de la práctica punitiva regulada) no se encuentra en definiciones de fines, pero que son definiciones de fines aquello que tiene potencial legitimatorio de ese objeto. Ellas se presentan de este modo a sí mismas como teorías de la pena ricas en contenido, pero en el ámbito dogmático asumen que las reflexiones sobre teoría de la pena no deben tener consecuencias. Esto es: asumiendo el diagnóstico de Rawls y Hart sobre la incompatibilidad del pensamiento sobre el sistema (o, en el lenguaje de Rawls: relativo a la justificación de una práctica) y el pensamiento en el sistema (o, en su lenguaje: sobre la justificación de acciones en una práctica $)^{30}$, las teorías de la pena de esta clase le asignan una función general al derecho penal sin pretender que esa definición tenga influencia en su interpretación interna. Con ello, el pensamiento teórico dentro del sistema se ve guiado por consideraciones relativas a la identidad interna de la práctica y no, en cambio, a su justificación en el entorno. De este modo pese a construir una identidad abiertamente rival de las teorías de la pena vacías, ellas son para nuestros efectos dogmáticamente equivalentes.

Paradigmático a este respecto es el trabajo de Andrew von Hirsch y Andrew Ashworth en el Reino Unido ${ }^{31}$, recibido y desarrollado en Alemania por Tatjana Hörnle ${ }^{32}$. Como la teoría de la pena designa aquí en realidad dos cuestiones distintas (la identificación del principio externo que justifica a la práctica en el entorno y la identificación del principio interno que permite reconstruir, a grandes rasgos, la identidad del sistema), y se trata de trabajos centrados en el segundo momento, las teorías de la pena en cuestión tienden a contentarse con mostrar que el derecho penal se caracteriza por su carácter expresivo de reproche (en ese sentido: orientación retributiva retrospectiva) y razonar a partir de ello en toda clase de problemas - sobre ello volveremos a propósito de la determinación de la pena. Estas clases de teoría entienden, sin embargo, que son críticas tanto de las teorías vacías como de las teorías retributivas ricas en contenido (asumiendo que alguien las defienda) por medio del reproche de que ellas desconocen la justificación instrumental del derecho penal ${ }^{33}$. Esto, por cierto, no es así, por lo que tiende a tratarse de disputas más bien sordas.

En cualquier caso: si se asume el punto de partida, metodológicamente correcto, de estas teorías, ellas llegan a la conclusión de que la teoría de la pena extra-sistemática es más bien

\footnotetext{
${ }^{30}$ Véase HART, H.L.A., "Prolegomenon to the Principles of Punishment", Proceedings of the Aristotelian Society, New Series, Vol. 60 (1960), pp. 1-26, pp. 8 y ss.; y RAWLS, John, "Two Concepts of Rules", The Philosophical Review, Vol. 64, $\mathrm{N}^{\circ} 1$ (1955), pp. 3-32, pp. 4 y ss. En la discusión alemana penal ya SCHMIDT, Die Aufgaben der Strafrechtspflege, cit. nota $\mathrm{n}^{\circ}$ 7, pp. 12 y ss. El punto reproduce, sin embargo, el problema teórico tradicional de la filosofía de las relaciones entre pensamiento intra-sistemático y extrasistemático.

${ }^{31}$ Véase, por ejemplo, VON HIRSCH, Andrew; y ASHWORTH, Andrew, Proportionate Sentencing, Oxford/Nueva York: Oxford University Press, 2005, pp. 12 y ss.

${ }^{32}$ HÖRNLE, Tatjana, Tatproportionale Strazumessung, Berlín: Duncker \& Humblot, 1999, pp. 112 y ss.

${ }^{33}$ En vez de muchos HÖRNLE, Tatjana, "Claus Roxin straftheoretischen Ansatz", en: HEINRICH et al (Eds.), Festschrift für Claus Roxin zum 80. Geburtstag, Berlín/Nueva York: De Gruyter, 2011, pp. 3-22, pp. 4 y ss.
} 
WILENMANN, Javier. “Contra las prácticas argumentativas de apelación a la "teoría de la pena" en la dogmática penal".

irrelevante: ella es ciertamente invocada como principio para explicar, por ejemplo, por qué existen cárceles y otras formas de castigo claramente orientados a la prevención ${ }^{34}$, pero en el pensamiento penal mismo el aspecto prospectivo apenas juega un rol. Esto se expresa ante todo en el hecho aparentemente llamativo de que proponentes de determinación de la pena en relación al hecho o a la culpabilidad se definan a sí mismos como prevencionistas $^{35}$, pero ello es natural a su punto de partida. Por supuesto: lo problemático de este modo de proceder es que tiende a naturalizar la definición del sistema (expresión de reproche) antes que en concentrarse en explicarla. Para nuestros efectos, sin embargo, se trata de teorías que confirman las dificultades de la pretensión meta-dogmática de la teoría de la pena.

\section{4. ¿Rendimientos pedagógicos de la teoría de la pena?}

Los argumentos anteriores debieran ser de por sí suficientes para demostrar que si la pretensión de la teoría de la pena es justificar una comprensión distintiva del derecho penal $\mathrm{y}$, a partir de ello, orientar las definiciones metodológicas autónomas de las ciencias penales, ella se encuentra mal construida. Teoría de la pena debiera ser teoría del derecho penal: no son particularidades en la función de la pena, sino en las nociones de responsabilidad sobre las que se construye, las que justifican la concesión de relevancia y autonomía que se le da al derecho penal. Con independencia del mérito que uno le otorgue al acercamiento moralizante que tiende a asumir hoy en día la academia jurídica a nivel mundial, en el derecho penal solo puede tratarse de algo así como un moral reading de las prácticas de imposición de castigo y no, en cambio, del castigo como medio estatal.

Pero tal vez la relevancia que se le otorga a las teorías de la pena no pretenda generar definiciones metodológicas fuertes, sino que tenga más bien una pretensión exclusivamente pedagógica: inculcar un espíritu determinado en todo sujeto que se aproxime al derecho penal, a saber, un espíritu de respeto y desconfianza hacia el objeto de estudio y, en particular, respecto de la pena como sanción. Iniciar el estudio del derecho penal con la pregunta por el fin de la pena a partir de la asunción platónica y hegeliana de que castigar por un hecho pasado es absurdo y luego plantear las posibles respuestas y sus críticas, contribuiría a tomar conciencia desde un inicio del carácter problemático del derecho penal, en condiciones que la exposición mediática a la popularidad del derecho penal probablemente produzca el acercamiento contrario. La teoría de la pena cumpliría, en ese sentido, una función pedagógica.

Aquí también es difícil dudar de que, en los hechos, la teoría de la pena cumple esta función. Pero intentar cumplir una función pedagógica a partir de un discurso que se sabe que finalmente no va a cuadrar parece ser más bien peligroso y obliga, por así decir, a

\footnotetext{
${ }^{34}$ VON HIRSCH/ASHWORTH, Proportionate Sentencing, cit. nota ${ }^{\circ} 31$, pp. 22 y ss.

${ }^{35}$ En el contexto continental, esta cuestión no ha sido ni especialmente relevante ni especialmente polémica. La cuestión es, en cambio, radicalmente distinta en el contexto anglosajón: los defensores de "teorías expresivas" y, en particular, von Hirsch y Ashworth como defensores del just deserts en la determinación de la pena han sido responsabilizados por jugar el juego de los conservadores y contribuir al aumento explosivo de las penas que ha tenido lugar en Estados Unidos y en el Reino Unido. Véase solo TONRY, Michael "Punishment", en: EL MISMO (Ed.), The Oxford Handbook of Crime and Criminal Justice, Nueva York: Oxford University Press, 2011, pp. 95-125, pp. 104 y ss.
} 
quedarse a medio camino. El estudiante y el operador jurídico-penal son expuestos al carácter inicialmente problemático del derecho penal y luego a considerar que hay respuestas convincentes que permitan superar ese carácter problemático y que son distintas del derecho penal, en condiciones que ello no es así. Probablemente sea mucho más razonable unir la orientación a la cautela en el estudio del derecho penal con una visión completa de aquello que pretende justificarlo: la unión del uso de los instrumentos más fuertes que tiene el Estado a su disposición a una comprensión de la responsabilidad anclada en la lógica del derecho abstracto y, con ello, el mantenimiento de la lógica del derecho abstracto.

\section{La insuficiencia de la teoría de la pena como instrumento con rendimiento dogmático-conceptual}

\subsection{Conceptos internos a la legislación penal y teoría de la pena}

Las reflexiones anteriores pueden tener un sesgo en realizar una asunción implícita respecto a que la teoría de la pena es, en su relevancia en el discurso académico jurídico, una teoría relativa a la reconstrucción de las condiciones generales de la punibilidad. En el lenguaje de la dogmática penal: la teoría de la pena encontraría su ámbito de influencia metodológica en la teoría general del delito a partir de definiciones de fines. Como hemos visto, el tipo de reflexión que anima a la teoría de la pena bajo esa definición funcional no puede jugar un papel metodológico demasiado importante en estos ámbitos. Las particularidades del derecho penal se encuentran antes en su vínculo con una concepción determinada de la responsabilidad, cuya institucionalización son las reglas tematizadas por la teoría general del delito. Su mejor versión es la de servir de lectura moral de la teoría del delito.

En esto, el argumento parece ser difícilmente contrarrestable: pensar prevencionistamente la teoría del delito implica incluso en una concepción utilitarista incurrir en una confusión entre pensamiento sobre una práctica y dentro de una práctica. La alternativa, el pensamiento retribucionista (o más generalmente: la invocación vacía a la teoría de la pena), es sin dudas correcto, pero esa corrección no deriva más que del hecho que el retribucionismo, a menos que sea lo que sus detractores le imputan -la creencia de que el castigo es un bien moral en sí-, no es más que la expresión intra-sistemática de la identidad del sistema penal y que, por lo mismo, no es una verdadera teoría de la pena en los términos en que se discute sobre ella.

Pero tal vez nuevamente el problema se encuentre en la fijación del objeto de reflexión de la teoría de la pena que hemos asumido. Existen ámbitos del derecho penal en que el pensamiento prevencionista o retribucionista parece jugar inmediatamente un rol relevante. El ámbito más relevante en que ello tiene lugar es (o debiera ser) central en el estudio y reconstrucción dogmática del derecho penal, pese a ser en general tratado con cierta dejación en nuestra tradición: la determinación de la cuantía de la pena y del modo de ejecución de esta (determinación de la pena en sentido amplio). En el contexto anglosajón, es usual que en aquellas ocasiones en que la discusión sobre teoría de la pena no es puramente moral o de justicia abstracta, ella se vincule ante todo a las consecuencias que ella tiene para estas prácticas (conocidas en el lenguaje jurídico en inglés como sentencing). Así, si bien la consideración (principal pero no exclusivamente) continental de que la teoría 
WILENMANN, Javier. “Contra las prácticas argumentativas de apelación a la "teoría de la pena" en la dogmática penal".

de la pena es ante todo relevante para determinar metodológicamente la reflexión sobre las condiciones de punibilidad parece no ser convincente, tal vez sí lo sea la consideración (principal pero no exclusivamente) anglosajona sobre que una reflexión de esta clase puede ser útil para determinar penas abstractas precisas y luego distribuir modos de ejecución.

En lo que sigue, criticaremos brevemente esta asunción en dos momentos. En primer lugar (3.2) distinguiremos dos clases de funciones que puede jugar la invocación a la teoría de la pena en discusiones dogmáticas: ella puede servir como modo de designación de la ratio legis (a veces: plausible) de algunas instituciones penales o ella puede servir como argumento desconectado de la ratio legis particular de una institución. La sección 3.2 pretende explicar esta distinción y dar cuenta de las razones por las que ello no es problemática en el primer caso y sí lo es en el segundo. Como modo de tratamiento más acabado de estos argumentos, en la sección 3.3 exploraremos, en cambio, la capacidad de rendimiento real de la teoría de la pena en el análisis de las prácticas de sentencing (determinación y ejecución de la pena).

\subsection{Funciones dogmáticas del lenguaje de la teoría de la pena}

En el análisis dogmático de las instituciones penales, las invocaciones a la teoría de la pena no son difíciles de encontrar. Ellas pueden tener lugar en instituciones de extinción de la responsabilidad penal como el indulto o la amnistía ${ }^{36}$, en el análisis de tipos penales de la Parte Especial al, por ejemplo, interpretar las reglas de calificación del homicidio ${ }^{37}$, en el análisis de causas de justificación ${ }^{38}$ o de las causas de exculpación ${ }^{39}$. Sin estar realmente omnipresente, se trata de una práctica extremadamente común. La práctica en cuestión esconde, sin embargo, dos clases de invocaciones cuya función es completamente distinta: puede tratarse de modos de designación fácilmente reconocibles (por lo conocidas y nítidas que son las categorías de la teoría de la pena) de la ratio legis plausiblemente atribuible a una institución determinada o puede tratarse de pretensiones de construcción de una continuidad sistemática entre la institución "derecho penal" en sí y sus distintas subinstituciones. Como veremos, lo primero no es en ningún caso problemático; pero no se trata de una verdadera invocación a la teoría de la pena, porque la finalidad que se le atribuye a la institución proviene de su propio contenido. El segundo caso constituye, en

\footnotetext{
${ }^{36}$ Para dar cuenta de lo extendida que está la práctica en cuestión, basta recordar que tanto el ex presidente Sebastián Piñera como el columnista y académico Carlos Peña, en un caso más ingenua, en el otro más sofisticada, hicieron invocaciones a argumentos de "fines" o "sentido" de la pena al dar cuenta sobre el sentido de alguna clase de indulto para militares condenados por delitos cometidos en la dictadura que se encontraran en condición de vejez o enfermedad terminal.

${ }^{37}$ En detalle sobre esta práctica WILENMANN, Javier, "El sistema de graduación de la pena del homicidio en el derecho chileno", Politica Criminal, Vol. 11, N²2 (2016), pp. 721-765, pp. 728 y ss.

${ }^{38}$ Esto es especialmente popular en la explicación de la justificación por necesidad agresiva. Ejemplar, en la tradición anglosajona, THORBURN, Malcolm, "Criminal Law as Public Law”, DUFF, Anthony y GREEN, Stuart P. (Eds.), Philosophical Foundations of Criminal Law, Oxford/Nueva York: Oxford University Press, 2013, pp. 21-47, pp. 31 y ss.

${ }^{39}$ En Alemania, la crítica probablemente más conocida a la dominante teoría de la doble disminución del disvalor de injusto en el estado de necesidad exculpante pretende ser una aplicación directa de consideraciones preventivas. Véase ROXIN, Claus, Strafrecht Allgemeiner Teil. Band I, 4. Edición, Múnich: C.H. Beck, 2006, $\S § 19$ Nm. 6 y 22 Nm. 6 y 11s. En Roxin, las reglas que componen a la categoría de la culpabilidad pretenden ser explicadas por apelaciones a argumentos de teoría de la pena.
} 
cambio, una verdadera pretensión de aplicación de teorías más generales y puede generar deformaciones dogmáticas.

Empecemos revisando el primer caso. Un ejemplo chileno: la institución de la interrupción de la prescripción de la acción penal (artículo 96 CP) o de la pena (artículo 99 CP). La prescripción se interrumpe en ambos casos cuando el imputado/condenado realiza un nuevo delito $^{40}$. Es difícil advertir qué justifica esta consecuencia, salvo una orientación "preventivo-especial" que permita mirar la realización de un nuevo delito como actualización del peligro que supone el imputado/condenado. Decir que se trata aquí de una "institución preventivo-especial" no implica, sin embargo, en ningún caso defender una teoría preventivo-especial o querer atribuirle a todo el derecho penal una orientación de esta clase, sino que es un simple modo de designación comunicativamente eficiente.

Por ello, que el lenguaje de la prevención o de la retribución sea directamente utilizado a propósito de ciertas instituciones no es necesariamente problemático y ello se justifica en la medida en que la pretensión atribuida a la institución pueda ser designada con relativa precisión mediante el lenguaje en cuestión. Uno puede, por cierto, criticar políticamente la orientación preventiva-especial de la institución de la interrupción de la prescripción o las pretensiones "puramente retributivas" de alguna otra institución, pero nada de esto tiene importancia para lo que nos interesa a nosotros: la crítica a la invocación con peso argumentativo real de la teoría de la pena no se juega ni en la crítica política a las instituciones penales ni en la interpretación (plausible) reconstruida con lenguaje típicamente utilizado a propósito de la teoría de la pena.

Distinta es la cuestión, en cambio, cuando la invocación a la "teoría de la pena" se inserta, por decirlo de un modo directo, en una especie de "gran narrativa" guiada por una definición general sobre el fin o el sentido general de la pena. La diferencia pragmática entre ambos casos se encuentra en la fuente en la atribución de "sentido" a la institución que se trata de interpretar: si la fuente es la institución misma, el problema se agota en determinar si la interpretación es plausible; si la fuente es el compromiso con una comprensión general del "sentido de la pena", la práctica argumentativa es en sí problemática.

Modos de argumentación de esta clase pueden ser reconocidos ante todo en la dogmática de la Parte General ${ }^{41}$. Pero ello también tiene lugar en la interpretación de tipos de la Parte Especial. Como hemos visto, en la dogmática del homicidio calificado, por ejemplo, no es inusual encontrar interpretaciones "preventivas" o "retributivas" de las reglas de calificación. Tanto las consideraciones que se encuentran detrás de las reglas discretas, como el tipo de argumentación que puede ser llevada a cabo para construir una dogmática sistemática del homicidio calificado, es mucho más rico que lo que supone este modo de hacer dogmático ${ }^{42}$.

\footnotetext{
${ }^{40}$ Sobre la historia dogmática de esta regla en la tradición continental véase ASHOLT, Martin, Verjährung im Strafrecht, Tubinga: Mohr Siebeck, 2016, pp. 21 y ss.

${ }^{41}$ Aquí también el ejemplo paradigmático se encuentra en la interpretación "político-criminal" de la teoría del hecho punible ligada a la obra de Claus Roxin. Véase solo ROXIN, $A T$, cit. nota $n^{\circ} 39, \S 7$ Nm. 57ss.

${ }^{42}$ WILENMANN, "Sistema de graduación de la pena”, cit. nota ${ }^{\circ} 37$, pp. 730 y ss.
} 
WILENMANN, Javier. “Contra las prácticas argumentativas de apelación a la "teoría de la pena" en la dogmática penal".

Estas reflexiones pueden ser ilustradas al llevar una exposición algo más precisa del problema de la "guía teórica" en las prácticas de determinación y ejecución de la pena (sentencing) en la próxima sección. Como veremos, en la invocación de la teoría de la pena se mezclan consideraciones de ambas clases, lo que produce distorsiones argumentativas relevantes.

\subsection{El caso de la determinación y ejecución de la pena como ejemplo de insuficiencia de la teoría de la pena}

La dogmática de la determinación de la pena (en sentido amplio: incluyendo cuestiones de determinación de la pena que efectivamente se ejecutará) es típicamente expresiva de tensiones metodológicas y políticas en la academia penal. La determinación de la pena no resulta por ello solo un aspecto crucial del funcionamiento institucional del derecho penal absolutamente descuidado en nuestra tradición, pese a que en Chile buena parte de la litigación penal sea en los hechos relativa a la determinación de la pena con el objeto de acceder a penas sustitutivas-, sino que aparece como un punto en que se cristalizan las tensiones políticas que encuentran expresión en la pretensión de interpretar al derecho penal mediante invocaciones a la teoría de la pena. Ello hace conveniente tratarla de modo detenido.

El análisis de la determinación de la pena requiere trazar, sin embargo, algunas distinciones. La primera distinción es relativa al objeto de la discusión: con el nombre de determinación de la pena (o similares: individualización, cuantificación) se conocen procesos distintos cuya posición sistemática no es siempre equivalente. Por ello, para especificar el objeto de discusión, podemos realizar una primera distinción fuerte entre discusiones relativas al mejor modelo de cuantificación de la pena (o, lo que es lo mismo, discusiones de lege ferenda) y discusiones relativas a la determinación de la pena en un sistema de derecho positivo ${ }^{43}$.

El primer tipo de discusiones ("cuantificación legislativa") es sistemáticamente perteneciente al ámbito de la política. La discusión política (si se quiere: sobre el sistema y no dentro del sistema) incluye cuestiones tales como cuáles son los criterios de cuantificación de la pena justa o necesaria a cada delito pero también relativa a cuáles son los criterios de determinación judicial de la pena que puede, o no, ser conveniente introducir. En tanto discusión política, ella no nos interesa directamente, pero aquí es obvio que la comprensión política que se tenga de la pena influye al menos parcialmente en todos estos elementos. Si uno quiere: la asunción de que la teoría (política) de la pena debe influir en la graduación de los tipos penales, no es especialmente problemática ${ }^{44}$, pese a que seguramente se vea limitada en su aparente obviedad por la necesidad de dar cuenta de intuiciones de proporcionalidad relativa por consideraciones de igualdad. Esa influencia es así tal vez demasiado nítida en el caso de propuestas de estructuración radicalmente

\footnotetext{
${ }^{43}$ Así incluso un defensor enérgico de continuidad teórica precisamente en base a la teoría de los fines de la pena como SPENDEL, Günter, Zur Lehre vom Strafmass, Fráncfort del Meno: Vittorio Klostermann, 1954, pp. 23 y ss.

${ }^{44}$ Ella es, por cierto, el centro de la polémica anglosajona sobre los modelos de sentencing.
} 


\section{Polít. crim. Vol. 12, № 24 (Diciembre 2017), Art. 4, pp. 754-785. \\ [http://www.politicacriminal.cl/Vol_12/n_24/Vol12N24A4.pdf]}

funcionales de sistemas penales ${ }^{45}$, las que asumen que el contenido de las instituciones penales debe ser el reflejo puro de una decisión funcional original. El caso más espectacular le corresponde probablemente a Bentham ${ }^{46}$ y a la versión moderna del utilitarismo penal en el análisis económico ${ }^{47}$. Pero por inverosímil que parezcan estas propuestas, esa inverosimilitud no les afecta como propuestas políticas. Sobre ello volveremos más adelante.

Por ahora nos interesa, en cambio, la determinación de la pena como disciplina propiamente dogmática, esto es, como un modo de reconstruir la forma en que los jueces deben razonar y justificar sus decisiones de imposición de una pena precisa en un sistema de derecho positivo en funcionamiento. Nos interesa en particular revisar la asunción, relativamente intuitiva, de que la pretensión meta-dogmática de la teoría de la pena encuentra su confirmación en la dogmática de la determinación de la pena.

En tanto análisis dogmático, la pregunta necesita ser tratada, sin embargo, bajo diferenciación de sistemas normativos: la comprensión de la determinación de la pena es distinta en sistemas con una regulación detallada y que pretende restringir fuertemente la discreción judicial (al modo de las Federal Sentencing Guidelines), en sistemas exactamente opuestos sin reglas sobre determinación del punto preciso de la pena (con lo que ella puede tender a ser tratada como simple cuestión de hecho o al menos como una operación no controlable y, por ello, completamente discrecional) ${ }^{48}$, en sistemas de fijación indeterminada de la cuantía de la pena ${ }^{49}$, en sistemas con regulaciones más o menos

\footnotetext{
${ }^{45}$ Lo problemáticas que pueden llegar a ser es mostrado por Frisch en relación con la comprensión de la determinación de la pena en Feuerbach: como la pena pretende influir preventivamente también en el autor, su magnitud debe depender de la tendencia a delinquir que pueda ser observada. Con ello mientras mayores pulsiones criminales posea o una estructura más rígida al aprendizaje (dada por ejemplo por defectos en la educación), mayor debe ser la pena. En el caso de autores reflexivos, el aprendizaje debiera lograrse más fácilmente. Véase FRISCH, Wolfgang, "Feuerbachs Straftheorie und seine Strafbemessungslehre", en: KOCH et al (Eds.), Feuerbachs Bayerische Strafgesetzbuch, Tubinga: Mohr Siebeck, 2013, pp. 191-208, pp. 201 y ss.

${ }^{46}$ BENTHAM, Jeremy, An Introduction to the Principles of Morals and Legislation, nueva edición, Oxford: Clarendon Press, 1823, pp. 178 y ss.: toda pena debe, como primera regla, tener idoneidad preventiva al infringir mayor dolor que el placer asociado al delito y, en principio, el dolor asociado a cada delito debe graduarse en atención al placer asociado a éste; pese a ello, las penas deben graduarse entre sí de modo proporcional al dolor que produzca cada delito, con el objeto de disponer subsidiariamente a la realización de los delitos que produzcan menos dolor; las penas deben agravarse en los casos en que el dolor relativo a un hecho es innecesariamente superior a su supuesto básico, de modo de desincentivarlo; y todo ello debe ser provisto del modo más barato posible. Notable en Bentham es que pese a su incontrolable pulsión por mantener un sistema consistente con sus asunciones generales, lo que debiera llevar a configurar un sistema en que la pena depende, en el fondo, del incentivo a la realización del delito, se vea compensada por la introducción de consideración de proporcionalidad bajo el argumento (no especialmente convincente en relación al íter de los delitos) de que el sistema debe hacer que el delincuente tienda a preferir la realización del delito menos dañoso.

${ }^{47}$ Locus classicus BECKER, Gary S., "Crime and Punishment: An Economic Approach", Journal of Political Economy, vol. 76, N² (1968), pp. 169-217, pp. 181 y ss.

${ }^{48}$ Véase respecto a esta asunción en la dogmática penal alemana de principios del siglo XX FRISCH, Wolfgang, "Straftatsystem und Strafzumessung", en: WOLTER, Jürgen, 140 Jahre Goltdammer's Archiv für Strafrecht, Heidelberg: R.v.Decker's Verlag, G. Schenck, 1993, pp. 1-38.

${ }^{49}$ Este es el modo en que funcionaban en general las prácticas de sentencing en los Estados Unidos antes de las reformas de los 70: los jueces condenaban a una pena determinada solo en un marco (x a y años) y la
} 
WILENMANN, Javier. “Contra las prácticas argumentativas de apelación a la "teoría de la pena" en la dogmática penal".

generales y relativas a un marco abierto (como en el caso del sistema alemán en aplicación del $\S 46 \mathrm{StGB}$ ) o en relación con un marco definido más allá de la calificación típica a partir de la aplicación taxada de atenuantes y agravantes al modo chileno (artículo $69 \mathrm{CP}$ ) o español (que no cuenta con una regla general de determinación de la extensión precisa de la pena, pero a cuyo respecto puede aplicarse el artículo 66 número 6 de la $\mathrm{CPE}$ ).

Como nuestra pregunta no es, por cierto, dogmático-positiva (es decir, no se trata de interpretar o postular criterios dentro de un sistema determinado), sino sobre el fundamento y modo de argumentación relativo a los criterios que deben influir en la cuantificación de la pena, nos interesa revisar la relevancia a asignarle a la invocación a la teoría de la pena aquí. La conclusión a ser defendida es relativamente enfática - poco o nada ${ }^{50}$, pero ello requiere de una pequeña explicación.

De forma mucho más clara que en el ámbito de discusión relativa a la punibilidad, la determinación de la pena es fácilmente comprensible como un caso de aplicación directa de la comprensión previa que se tenga de la justificación de la pena ${ }^{51}$. El vínculo parece ser natural: si el juez tiene un margen necesario de discrecionalidad en sistemas en que la calificación típica solo permite determinar márgenes dentro de los que debe enmarcarse la pena concreta a ser cumplida -excepción: las denominadas "penas absolutas", esto es, tipos penales que contempla solo una pena no graduable (pena de muerte, prisión perpetua), sin alternativas positivamente reconocidas-, entonces parece natural que, dada la naturaleza necesariamente argumentativa del paso ulterior de especificación ${ }^{52}$, los criterios justificatorios de la decisión relativa a la pena precisa sean relativos a la función que ella debe cumplir. 53

Especialmente prístino en esta asunción es la sumamente influyente reconstrucción de Roxin del modo en que influyen entre sí las distintas funciones de la pena en los distintos momentos de funcionamiento del sistema penal: mientras la conminación (legislación) debiera orientarse de modo exclusivamente preventivo y por exigencias de culpabilidad y

decisión sobre el momento de término de la pena era dejada a las autoridades administrativas encargadas del parole. Al respecto véase JOHNSON, Brian, "Sentencing", en: TONRY, Michael (Ed.), The Oxford Handbook of Crime and Criminal Justice, Nueva York: Oxford University Press, 2014, pp. 696-729.

${ }^{50}$ Similar HÖRNLE, Tatproportionale Strazumessung, cit. nota ${ }^{\circ} 32$, pp. 125 y ss.; SILVA SÁNCHEZ, Jesús María, "La teoría de la determinación de la pena como sistema (dogmático): un primer esbozo", InDret $\mathrm{N}^{\circ} 2$ (2007), pp. 5 y ss.

${ }^{51}$ Esta es la asunción sobre la que se estructura el extraordinariamente influyente escrito de habilitación de SPENDEL, Zur Lehre vom Strafmass, cit. nota $\mathrm{n}^{\circ}$ 43, pp. 197 y ss. A favor de la idea de realización (relativamente) directa de los fines de la pena véanse también los influyentes trabajos de ZIPF, Heinz, Die Strafzumessung, Heidelberg/Karlsruhe: C.F. Müller, 1977, pp. 23 y ss., 46 y ss.; BRUNS, Hans-Jürgen, Leitfaden des Strafzumessungsrechts, Colonia/Berlín/Bonn/Múnich: Carl Heymanns, 1980, pp. 6 y ss., 63 y ss. Sobre la asunción en cuestión en la dogmática alemana véase HÖRNLE, Tatproportionale Strazumessung, cit. nota ${ }^{\circ}$ 32, pp. 125 y ss.; FRISCH, "Straftatsystem und Strafzumessung", cit. nota n ${ }^{\circ} 48$, pp. 6 y ss.; EL MISMO, "Zur Bedeutung von Schuld, Gefährlichkeit und Prävention im Rahmen der Strafzumessung", en: EL MISMO (Ed.), Grundfragen des Strafzumessungsrechts aus deutscher und japanischer Sicht, Tubinga: Mohr Siebeck, 2011, pp. 3-26, pp. 4 y ss.

${ }^{52}$ Véase a este respecto HASSEMER, Winfried, "Die rechtstheoretische Bedeutung des gesetzlichen Strafrahmens", en: KAUFMANN, Arthur (Ed.), Gedächtnisschirift für Gustav Radbruch, Gotinga: Vandenboeck \& Ruprecht, 1968, pp. 281-290, pp. 284 y ss.

${ }^{53}$ Así claramente ORMEROD, Smith and Hogan's Criminal Law, cit. nota n 19, pp. 37 y ss. 
mientras que la determinación de la punibilidad no puede verse guiada por consideraciones de esta clase, la determinación de la pena sería el momento en que revive la orientación preventiva del sistema, aunque limitada por el principio de culpabilidad (que en este caso debe ser el marco penal) ${ }^{54}$. Aquí no nos interesa demasiado si la teoría "dialéctica de la unión" de Roxin es en sí convincente o inconsistente ni si tiene buenos fundamentos a su favor, sino que se trata de destacar que ella expresa intuiciones generales sobre pertinencia directa pero limitada de la teoría de la pena al momento de su determinación.

Un trabajo dogmático sobre la determinación de la pena debiera, por ello, orientarse a hacer controlable la pretensión de realización de la función de la pena que subyacería al juicio de determinación de la pena por medio de una sistemática adecuada. El influyente trabajo de Spendel ofrecía una articulación de esta clase: el fundamento final de la determinación de la pena es la teoría de la pena, pero ella se articula a partir de juicios relativos a hechos reales (Strafzumessungsgründe) con un nivel de especificación mayor ${ }^{55}$. Con ello, un autor retribucionista debiera tender a señalar que la determinación de la pena no puede estar afecta a pronósticos preventivos sino a una graduación del merecimiento de reproche del hecho a partir de determinados supuestos de hecho; la apertura de la regulación a consideraciones preventivas debiera, en cambio, ser favorecida por autores que se definan a sí mismos como prevencionistas. Siguiendo esta misma tendencia, el hecho de que la regulación disponga que el juez debe realizar pronósticos preventivos o que, en cambio, la magnitud de la pena dependa de la gravedad del hecho, debiera ser tomado como argumento a favor de que una u otra teoría es la teoría de la pena asumida por el sistema ${ }^{56}$.

Aquí podemos volver sobre las distinciones que trazamos en la sección 3.2 para analizar el potencial de rendimiento de este modo de razonamiento dogmático: si la apelación a la teoría de la pena juega el rol de simple designación de una pretensión fácilmente atribuible a reglas positivas de determinación de la pena, no es demasiado lo que uno puede criticar dogmáticamente, pero no se trata de invocaciones a la teoría de la pena en el sentido que nos interesa. Ejemplo: si las reglas mandan a considerar el "peligro de perpetración de nuevos delitos" o "el tiempo necesario a la resocialización del condenado", no es demasiado elocuente por ahora decir que no hay una pretensión "preventivo-especial"

\footnotetext{
${ }^{54}$ Véase ROXIN, $A T$, cit. nota ${ }^{\circ} 39, \S 3$ Nm. 37ss.

${ }^{55}$ Menos enfático HASSEMER, "Die rechtstheoretische Bedeutung”, cit. nota ${ }^{\circ}$ 52, pp. 286 y ss.: el juicio de calificación típica, en tanto juicio clasificatorio, es esencialmente conceptual y cerrado a la valoración vital de las decisiones que se toman. El juicio de determinación de la pena, dada su imposibilidad de constituirse en simple subsunción, es una apertura pragmática limitada (por el marco dependiendo del proceso de calificación típica) a la vitalidad de la decisión que se toma.

${ }^{56} \mathrm{La}$ relevancia que los autores en los hechos le atribuyen a decisiones de esta clase es tan obvia que la Sentencing Commission advierte al inicio de las Federal Sentencing Guidelines (USSG Ch. 1 Pt. A, pp. 4 y ss.) que una dificultad central en el cumplimiento de su labor fue enfrentarse a la pretensión de que decidiera entre una orientación preventiva o retributiva a la determinación de la pena. Viendo la problemática políticojudicial (y político-académica) que ello significaba, la comisión señala que no debió optar por esa decisión, ya que ambos enfoques llevarían a la misma solución. Similar, aunque asumiendo el carácter de "ventaja práctica" de un sistema de determinación de la pena centrado en el hecho, FRISCH, "Zur Bedeutung", cit. nota $\mathrm{n}^{\circ} 51$, pp. 6 y ss.: mientras la orientación preventiva directa requiere de imposición de una visión del derecho penal, centrarse en el hecho sería compatible con teorías de la pena alternativas. No es relevante dar cuenta si ese diagnóstico es correcto; solo la expectativa puesta por los académicos en las fijaciones autoritativas sobre determinación de la pena.
} 
WILENMANN, Javier. “Contra las prácticas argumentativas de apelación a la "teoría de la pena" en la dogmática penal".

vinculada a las reglas de derecho positivo en cuestión. Por supuesto, sabiendo que las reglas generales sobre la punibilidad se orientan retrospectivamente, la integración de modos de razonamiento preventivo tiende a llamar la atención y, a la Spendel, ello es utilizado para decir que aquí sí que hay influencia de la teoría de la pena. Pero correctamente entendido, no se trata más que de la concesión de potestades de razonamiento preventivo limitadas por marcos preestablecidos; no hay ni confirmación de una teoría de la pena preventiva en sistemas que hacen uso de reglas de esta clase ni confirmación de una teoría de la pena retributiva en sistemas que no lo hacen.

Quien defienda la interpretación del derecho penal a partir de un compromiso fuerte con una "teoría de la pena" seguramente diría a este respecto que declarar que no hay más que concesión de competencias bajo modos de razonamiento preventivos es ser "simplemente positivista", rompiendo la unidad sistemática del derecho penal. Pero las unidades sistemáticas se construyen allí donde pueden mantenerse; una extensión excesiva necesariamente lleva a planteamientos inverosímiles o a reconstrucciones sistemáticas vacías. Distinta es, por cierto, la pregunta por el fundamento de un trato preventivo cuando la responsabilidad se establece bajo la pura idea de responsabilidad racional por el hecho pasado. La respuesta no es, sin embargo, difícil de producir: porque la responsabilidad pasada autoriza a un modo de trato políticamente fijado y esa fijación política puede incluir (bajo límites trazados por el sistema) orientaciones preventivas.

Pese a lo anterior, es posible ir incluso un poco más lejos en el caso de la interpretación de las reglas de la determinación de la pena. Aquí es incluso posible afirmar que sin una configuración institucional adecuada, el funcionamiento "preventivo-especial" de la práctica tiende a ser completamente limitado pese a la existencia de reglas que manden a consideraciones pronósticos de peligro individual ${ }^{57}$. Las razones son conocidas ${ }^{58}$. Un sistema efectivamente orientado a determinar la pena que le corresponde a un autor en base a alguna clase de pronóstico efectuado al momento de la determinación de la pena (tendencia a redelinquir, tiempo individualmente necesario para neutralizar o resocializar al individuo) debiera contar en los hechos con instituciones orientadas a la realización de pronósticos (que pueden ser objeto de incidente y prueba) sobre comportamientos futuros del autor o de otros ${ }^{59}$. Esto no solo puede ser criticado por la posibilidad de conducir a juicios estrictamente orientados a evaluar al autor y a su vida y no, en cambio, al hecho,

\footnotetext{
57 Así, por ejemplo, FRISCH, "Straftatsystem und Strafzumessung", cit. nota n 48, pp. 20 y ss.: "estabilización de las normas"; VON HIRSCH/JAREBORG, Strafmaß und Strafgerechtigkeit, cit. nota $n^{\circ} 21$, pp. 11 y ss.: "expresión de reproche conforme a merecimiento"; HART-HÖNIG, Kai, Gerechte und zweckmäßige Strafzumessung, Berlín: Duncker \& Humblot, 1992, pp. 98 y ss.

${ }^{58}$ Véase a este respecto STAHL, Dominik, Strafzumessungstatsachen zwischen Verbrechenslehre und Straftheorie, Berlín: Duncker \& Humblot, 2015, pp. 148 y ss.; HÖRNLE, Tatproportionale Strazumessung, cit. nota $\mathrm{n}^{\circ}$ 32, pp. 77 y ss. Ellas se refieren, por cierto, ante todo a teorías preventivas. Pero tomar esto a favor de una teoría retributiva o de alguna clase de teoría preventiva vacía (al modo de la prevención general positiva) solo es una consecuencia de que esas son clases de teorías de la pena que, en realidad, son negativas, esto es, son no-teorías de la pena metodológicamente consideras (i.e.: no asumen que la teoría de la pena pueda tener un carácter meta-dogmático).

59 Sobre la debilidad de las argumentaciones aparentemente preventivas que pueden encontrarse en la jurisprudencia alemana STAHL, Strafzumessungstatsachen zwischen Verbrechenslehre und Straftheorie, cit. nota $\mathrm{n}^{\circ} 58$, pp. 148 y ss.
} 
sino que institucionalmente implica la asunción de un nivel de complejidad inmanejable y completamente irrealista incluso en países con instituciones fuertes ${ }^{60}$.

Incluso más: asumiendo hipotéticamente ausencia de escasez de recursos -esto es: que los jueces cuenten con un extenso soporte pericial orientado individualmente a la realización de diagnósticos y pronósticos sobre cada condenado antes de la determinación de la pena, cuyas conclusiones sean objeto de un incidente litigioso real- no parece sensato asumir que sea posible realizar frecuentemente juicios de esta clase, ya que los factores que permiten la realización de un diagnóstico no se encuentran siempre presentes ${ }^{61}$. Dicho de otro modo: la pretensión de estructurar un sistema institucional de distribución de la pena en base a consideraciones directamente consecuencialistas es inviable por escasez de recursos estatales y por escasez de indicios de pronóstico ${ }^{62}$. Con ello, precisamente a causa de que las reglas de determinación de la pena tienden a hacer uso de un lenguaje también preventivo-especial (instructivo $\S 46$ inciso segundo StGB), su interpretación en esos términos es más bien limitada y tiende a abordar casi exclusivamente la pregunta por la valoración general de antecedentes penales.

Con ello, sorprendentemente la regla es más bien la contraria a la que asume la tesis de la conexión: la dogmática determinación de la pena tiende a construirse en ruptura con consideraciones funcionales sobre la pena. $\mathrm{Su}$ estructuración relativa a clases de razonamientos que caracterizan antes al razonamiento de punibilidad -en ruptura institucional necesaria con la teoría de la pena-, asumida en buena medida por las investigaciones más convincentes de la literatura actual, simplemente confirma esto ${ }^{63}$.

60 En esto, especialmente ingenuo KASPAR, Verhältnismäßigkeit und Grundrechtsschutz im Präventionsstrafrecht, cit. nota $\mathrm{n}^{\circ} 11$, pp. 285 y ss.: la determinación de la pena "orientada a la culpabilidad" sería problemática por justificar la extensión de la lesión de un derecho fundamental sin referencia a datos empíricos de necesidad en la prevención futura de otros hechos.

61 A este respecto fundamental FRISCH, Wolfgang, Prognoseentscheidungen im Strafrecht, Heidelberg/Hamburgo: R.v.Decker's Verlag, G. Schenck, 1983, pp. 23 y ss., 57 y ss.; EL MISMO, “Zur Bedeutung", cit. nota $\mathrm{n}^{\circ}$ 51, pp. 7 y ss. Véase también HÖRNLE, Tatproportionale Strazumessung, cit. nota $\mathrm{n}^{\circ} 32$, pp. 85 y ss.; HART-HÖNIG, Gerechte und zweckmäßige Strafzumessung, cit. nota ${ }^{\circ} 57$, pp. 52 y ss. En general, se asume que la orientación en base a pronósticos en la determinación de la pena es inviable. Ello deja abierto, sin embargo, el problema paralelo sobre la viabilidad de la orientación a pronósticos en decisiones que son catalogadas de "ejecución" de la pena, como sucede ante todo en la pregunta central sobre si se sustituye la privación de libertad. Aquí sí que parece obvio que el sistema debe orientarse a realizar pronósticos y las leyes de hecho tienden a hacerlo. Pero el diagnóstico institucional es el mismo: el problema es casi igualmente masivo, los tribunales nunca cuentan con recursos para que los pronósticos sean generalmente realizados y controvertidos y en los casos individuales tiende a haber ausencia de hechos bases que permitan realizar un diagnóstico del todo. Pese a ello, la condición binaria de la decisión ofrece una salida a este problema: declarar que la regla general es la sustitución, cuando ella procede formalmente, y constituir al diagnóstico en fundamento de toma de la decisión excepcional, con carga probatoria, por ello, en el Estado. Así convincentemente FRISCH, Prognoseentscheidungen im Strafrecht, pp. 50 y ss. Este es, por lo demás, el modo en que tienden a funcionar las instituciones.

${ }^{62}$ La cuestión es ciertamente distinta en sistemas en que el pronóstico sea efectuado después de observación extensa del comportamiento del condenado, esto es, en los sistemas de indeterminate sentencing. Allí el número de posibles hechos indiciarios en la realización de un pronóstico debe aumentar significativamente, con lo que la escasez debe tender a reducirse. Esa es la razón por la que sistemas asociados a "pretensiones de rehabilitación", pero también a neutralización, operan con arreglos de esta clase.

${ }^{63}$ FRISCH, Wolfgang, "Über das Verhältnis von Straftatsystem und Strafzumessung. Unrecht und Schuld in der Verbrechenslehre und in der Strafzumessung”, Goltdammer's Archiv für Strafrecht, 2014, pp. 489-503, 
WILENMANN, Javier. “Contra las prácticas argumentativas de apelación a la "teoría de la pena" en la dogmática penal".

Por supuesto, nada de esto impide que la ley haga uso de estándares con orientación preventiva. Decisiones de esta clase pueden ser objeto de crítica política -ante todo política institucional: la crítica alemana a la capacidad de funcionamiento de orientaciones preventivas en etapa de determinación de la pena parece ser terminante-, pero ninguna concepción teórica impide que ello tenga lugar. Seguro es una cosa: la dogmática de la determinación de la pena tiene independencia teórica en relación a las discusiones sobre la legitimidad política de la pena.

\section{Conclusiones}

Las prácticas argumentativas de apelación a la "teoría de la pena" son problemáticas tanto como expresiones de definición metodológica de la dogmática penal como en su pretensión de constituir argumentos dogmáticos directos. La suposición que subyace a esta clase de argumentos, en el sentido de que la pena tendría fines específicos y que el pensamiento respecto a esos fines puede conducir a la dogmática, no puede encontrarse justificado dada la artificialidad de la pena y del sistema penal. Como conjunto de reglas, el derecho penal no tiene características que lo distingan de otras ramas del ordenamiento jurídico en relación a las funciones que puede cumplir. A este sí subyacen, en cambio, nociones sustantivas sobre la idea de responsabilidad que encuentran su manifestación en las reglas de imputación que lo caracterizan, por lo que pensamiento "sustantivo" penal debiera ser antes lectura moral de las condiciones de imposición del castigo que lectura moral de la práctica de castigar o de los fines de la pena.

También en el ámbito de la argumentación propiamente dogmática (y no metadogmática) la invocación a argumentos de teoría de la pena resulta problemática. Ello no tiene lugar porque ninguna institución penal particular tenga fines preventivos específicos o se le puedan atribuir finalidades compatibles con aquellas identificadas tradicionalmente por el discurso de la teoría penal. Al contrario, bien puede ser que el derecho positivo reconozca instituciones con fines preventivos y modos de acción en la prevención compatibles con las ideas de "prevención general" o "prevención especial". Pero nada de esto participa de una gran narrativa teórica; la configuración de las instituciones bajo atribución de esas finalidades es antes el simple reflejo de una prerrogativa política. Esta es, de hecho, la realidad general que a la academia penal le ha costado históricamente asumir, a saber, que estudian instituciones políticas con fines cambiantes y relativamente abiertas a esas variaciones de fines.

pp. 489 y ss.; EL MISMO, “Straftatsystem und Strafzumessung”, cit. nota ${ }^{\circ}$ 48, pp. 13 y ss.; HÖRNLE, Tatproportionale Strazumessung, cit. nota $\mathrm{n}^{\circ} 32$, pp. 143 y ss.; Similar, aunque sin hacer referencia a la teoría del hecho punible, VON HIRSCH/JAREBORG, Strafmaß und Strafgerechtigkeit, cit. nota ${ }^{\circ} 21$, pp. 26 y ss.: la determinación de la pena depende de consideraciones de justicia que se traducen en proporcionalidad relativa a otros hechos delictivos (asumiendo un principio de igualdad) y proporcionalidad en relación con el nivel de represión que, en las convenciones del sistema, merece un hecho determinado. Von Hirsch y Jareborg conectan esto con la intuición de que la pena es expresiva de reproche y ello se basa en consideraciones de igualdad. Pero el argumento de igualdad en la represión no depende del carácter expresivo de la pena; es igualmente aplicable respecto de sanciones sin componente represivo. 
Polít. crim. Vol. 12, No 24 (Diciembre 2017), Art. 4, pp. 754-785.

[http://www.politicacriminal.cl/Vol_12/n_24/Vol12N24A4.pdf]

\section{LISTADO BIBLIOGRÁFICO}

APPEL, Ivo, Verfassung und Strafe, Berlin: Duncker \& Humblot, 1996.

ASHOLT, Martin, Verjährung im Strafrecht, Tubinga: Mohr Siebeck, 2016.

BAUER, Anton, Die Warnungstheorie, reimpresión Goldbach: Keip Verlag, 1996. , Lehrbuch des Strafrechts, reimpresión Goldbach: Keip Verlag), 1996.

BECKER, Gary S., "Crime and Punishment : An Economic Approach Approach", Journal of Political Economy, Vol. 76, N 2 (1968), pp. 169-217.

BELING, Ernst, Die Vergeltungsidee und ihre Bedeutung für das Strafrecht, reimpresión Aalen: Scientia Verlag, 1978.

BENTHAM, Jeremy, An Introduction to the Principles of Morals and Legislation, nueva edición, Oxford: Clarendon Press, 1823.

BÖCKENFÖRDE, Ernst-Wolfgang, Staat, Verfassung, Demokratie, 2. Edición, Fráncfort del Meno: Suhrkamp, 1992.

BRUDNER, Alan, Punishment and Freedom, Oxford/New York: Oxford University Press, 2009.

BRUNS, Hans-Jürgen, Leitfaden des Strafzumessungsrechts, Colonia/Berlín/Bonn/Múnich: Carl Heymanns, 1980.

BUSTOS RAMÍREZ, Juan, "Kriminalpolitik und Strafrecht”, en: HIRSCH, Hans Joachim; KAISER, Günther; MARQUARDT, Helmut (Eds.), Gedächnitsschrift für Hilde Kaufmann, Heidelberg/Múnich/Landsberg/Berlín: De Gruyter, 1986, pp. 69-88.

FARMER, Lindsay, "Criminal Law as an Institution", en: DUFF et al (Eds.), Criminalization. The Political Morality of the Criminal Law, Oxford/New York: Oxford University Press, 2014, pp. 80-100.

FEUERBACH, Paul Johann Anselm, Lehrbuch des gemeinen in Deutschland gültigen peinlichen Rechts, reimpresión, Aalen: Scientia Verlag, 1986.

, Revision der Grundsätze und Grundbegriffe des positiven peinlichen Rechts, reimpresión, Aalen: Scientia Verlag, 1966.

FRISCH, Wolfgang, "Feuerbachs Straftheorie und seine Strafbemessungslehre", en: KOCH et al (Eds.), Feuerbachs Bayerische Strafgesetzbuch, Tubinga: Mohr Siebeck, 2013, pp. 191-208.

, Prognoseentscheidungen im Strafrecht, Heidelberg/Hamburgo: R.v.Decker's Verlag, G. Schenck, 1983.

, "Straftatsystem und Strafzumessung", en: WOLTER, Jürgen (Ed.), 140 Jahre Goltdammer's Archiv für Strafrecht, Heidelberg: R.v.Decker's Verlag, G. Schenck, 1993, pp. 1-38.

, "Über das Verhältnis von Straftatsystem und Strafzumessung. Unrecht und Schuld in der Verbrechenslehre und in der Strafzumessung", Goltdammer's Archiv für Strafrecht, 2014, 489-503.

, "Zur Bedeutung von Schuld, Gefährlichkeit und Prävention im Rahmen der Strafzumessung", en: FRISCH, Wolfgang (Ed.), Grundfragen des Strafzumessungsrechts aus deutscher und japanischer Sicht, Tubinga: Mohr Siebeck, 2011, pp. 3-26.

GÄRDITZ, Klaus Ferdinand, "Strafbegründung und Demokratieprinzip", Der Staat, 49 (2010), 331-67.

GARLAND, David, Punishment and Modern Society, Oxford/New York: Oxford 
WILENMANN, Javier. “Contra las prácticas argumentativas de apelación a la "teoría de la pena" en la dogmática penal".

University Press, 1990.

GRECO, Luis, "Verfassungskonformes oder legitimes Strafrecht? Zu den Grenzen einer verfassungsrechtlichen Orientierung der Strafrechtswissenschaft", en: BRUNHÖBER et al (Eds.), Strafrecht und Verfassung, Baden-Baden: Nomos, 2013, pp. 13-36.

VON GROLMAN, Karl, Grundsätze der Criminalrechtswissenschaft, reimpresión, Goldbach: Keip Verlag, 1996.

GÜNTHER, Klaus, "Die Zuschreibung strafrechtlichen Verantwortlichkeit auf der Grundlage des Verstehens”, en: LÜDERSSEN, Klaus (Ed.), Aufgeklärte Kriminalpolitik oder Kampf gegen das Böse?, Baden-Baden: Nomos, 1998, pp. 319349.

, Schuld und kommunikative Freiheit, Fráncfort del Meno: Vittorio Klostermann, 2005.

HART-HÖNIG, Kai, Gerechte und zweckmäßige Strafzumessung, Berlín: Duncker \& Humblot, 1992.

HART, H.L.A., "Prolegomenon to the Principles of Punishment", Proceedings of the Aristotelian Society, New Series, 60 (1960), pp. 1-26.

HASSEMER, Winfried, "Die rechtstheoretische Bedeutung des gesetzlichen Strafrahmens", en: KAUFMANN, Arthur (Ed.), Gedächtnisschirift für Gustav Radbruch, Göttingen: Vandenboeck \& Ruprecht, 1968, pp. 281-290.

VON HIRSCH, Andrew y ASHWORTH, Andrew, Proportionate Sentencing, Oxford/New York: Oxford University Press, 2005.

VON HIRSCH, Andrew y JAREBORG, Nils, Strafmaß und Strafgerechtigkeit, Bonn: Forum Verlag Godesberg, 1991.

HORDER, Jeremy, "Bureaucratic 'Criminal' Law”, en: DUFF et al (Eds.), Criminalization. The Political Morality of the Criminal Law, Oxford/New York: Oxford University Press, 2014, pp. 103-131.

HÖRNLE, Tatjana, "Claus Roxin straftheoretischen Ansatz", en: HEINRICH et al (Eds.), Festschrift für Claus Roxin zum 80. Geburtstag, Ed.: Berlín/Nueva York: De Gruyter, 2011, pp. 3-22.

, Tatproportionale Strazumessung, Berlín: Duncker \& Humblot, 1999.

HUSAK, Douglas, Overcriminalization, Oxford/New York: Oxford University Press, 2008.

JAKOBS, Günther, Strafrecht Allgemeiner Teil, 2., Berlín/Nueva York: De Gruyter, 1991.

JELLINEK, Georg, Allgemeine Staatslehre, 3. Edición, Darmstadt: Wissenschaftliche Buchgesellschaft, 1960.

, Die sozialethische Bedeutung von Recht, Unrecht und Strafe, 2. Edición, Berlín: Verlag von O. Häring, 1908.

JOHNSON, Brian, "Sentencing", en: TONRY, Michael (Ed.), The Oxford Handbook of Crime and Criminal Justice, New York: Oxford University Press, 2014, pp. 696-729

KASPAR, Johannes, Verhältnismäßigkeit und Grundrechtsschutz, im Präventionsstrafrecht, Baden-Baden: Nomos, 2014.

KINDHÄUSER, Urs, "Rechtstreue als Schuldkategorie", Zeitschrift für die internationale Strafrechtsdogmatik, 1995, pp. 701-733.

, "Strafrechtliche Schuld im demokratischen Rechtsstaat", en: HERZOG, Felix y NEUMANN, Ulfried (Eds.), Festschrift für Winfried Hassemer zum 70. Geburtstag, Heidelberg: Carl Heymanns, 2010, pp. 761-774.

KLEINFELD, Joshua, "Reconstructivism: the Place of Criminal Law in Ethical Life", 
Polít. crim. Vol. 12, No 24 (Diciembre 2017), Art. 4, pp. 754-785.

[http://www.politicacriminal.cl/Vol_12/n_24/Vol12N24A4.pdf]

Harvard Law Review, Vol. 129, N 6 (2016), pp. 1485-1565.

LACEY, Nicola, "Legal constructions of crime", en: MAGUIRE, Mike; MORGAN, Rod; REINER, Robert (Eds.), The Oxford Handbook of Criminology, Ed.:, Oxford/New York: Oxford University Press, 2007, pp. 179-200.

LAMOND, Grant, "What is a Crime?", Oxford Journal of Legal Studies, Vol. 27, N 4 (2009), pp. 609-632.

MACCORMICK, Neil, Institutions of Law: an Essay in Legal Theory, Oxford/New York: Oxford University Press, 2007.

MAÑALICH, Juan Pablo, "Retribucionismo consecuencialista como programa de ideología punitiva. Una defensa de la teoría de la retribución de Ernst Beling”, InDret, 2 (2015).

MARX, Karl, "Über die Todestrafe - Herrn Cobdens Pamphlet", en: Karl Marx/Friedrich Engels - Werke, Band 8, 3. Edición, Berlín Oriental: Karl Dietz Verlag, 1972, pp. 506-513.

MERKEL, Adolf, Vergeltungsidee und Zweckgedanke im Strafrecht, Estrasburgo, Verlag von Karl J. Trübner, 1892.

VON MOHL, Robert, Die Polizei-Wissenschaft nach den Grundsätzen des Rechtsstaates. Dritter Band: System der Präventiv-Justiz, 3. Edición, Tubinga: Verlag der H. Laupp'schen Buchhandlung, 1866.

MÖLLERS, Christoph, Gewaltengliederung, Tubinga: Mohr Siebeck, 2005.

MOORE, Michael, “Justifying Retributivism”, Israel Law Review, Vol. 27, № 1-2 (1993), pp. 15-49.

MURPHY, Jeffrie, Retribution, Justice and Therapy, Dordrecht: Reidel Publishing Company, 1979.

ORMEROD, David, Smith and Hogan's Criminal Law, 13. Edición, Oxford/Nueva York: Oxford University Press, 2011.

PIONTKOWSKI, A.A., Hegels Lehre über Staat und Recht und seine Strafrechtstheorie; LEKSCHA, John (Trad.), Berlín Oriental: VEB Deutscher Zentralverlag, 1960.

RAMSAY, Peter, "The Responsible Subject as Citizen: Criminal Law, Democracy and the Welfare State", The Modern Law Review, Vol. 69, N 1 (2006), pp. 29-58.

RAWLS, John, "Two Concepts of Rules", The Philosophical Review, Vol. 64, № 1 (1955), pp. 3-32.

RISTROPH, Alice, “Just Violence”, Arizona Law Review, Vol. 56, № 4 (2014), pp. 10171063.

ROXIN, Claus, Strafrecht Allgemeiner Teil. Band I, 4. Edición, Múnich: C.H. Beck, 2006.

SCHMIDT, Richard, Die Aufgaben der Strafrechtspflege, Leipzig: Duncker \& Humblot, 1895.

Einführung in die Rechtswissenschaft, 2. Edición, Leipzig: Felix Meiner, 1923.

SILVA SÁNCHEZ, Jesús María, "La teoría de la determinación de la pena como sistema (dogmático): un primer esbozo", InDret N² (2007).

SPENDEL, Günter, Zur Lehre vom Strafmass, Fráncfort del Meno: Vittorio Klostermann, 1954.

STAHL, Dominik, Strafzumessungstatsachen zwischen Verbrechenslehre und Straftheorie, Berlín: Duncker \& Humblot, 2015.

STOLLEIS, Michael, "Entwicklungsstufen der Verwaltungsrechtswissenschaft", en: HOFFMAN-RIEM, Wolfgang; SCHMIDT-AßMANN, Eberhard y VOßKUHLE, 
WILENMANN, Javier. “Contra las prácticas argumentativas de apelación a la "teoría de la pena" en la dogmática penal".

Andreas (Eds.), Grunlagen des Verwaltungsrechts. Band I, Múnich: Beck, 2006, pp. 63-119.

THORBURN, Malcolm, "Criminal Law as Public Law", en: DUFF, Anthony y GREEN, Stuart P. (Eds.), Philosophical Foundations of Criminal Law, Oxford/Nueva York: Oxford University Press, 2013, pp. 21-47.

TIEDEMANN, Klaus, Verfassungsrecht und Strafrecht, Heidelberg: C.F. Müller, 1991.

TONRY, Michael, "Obsolescence and Immanence in Penal Theory and Policy Author", Columbia Law Review Vol. 105, N 4 (2005), pp. 1233-1275.

, "Punishment", en: TONRY, Michael (Ed.), The Oxford Handbook of Crime and Criminal Justice, Nueva York: Oxford University Press, 2011, pp. 95-125.

VOLK, Klaus, "Alles Strafe, oder was? - Zum Begriff der Strafe", en: JUNG, Heike; LUXENBURGER, Bernd y WAHLE Eberhard (Eds.), Festschrift für Egon Müller, Baden-Baden: Nomos, 2008, pp. 709-715.

VON WÄCHTER, Carl Georg, Lehrbuch des Römisch - Teutschen Strafrechts, reimpresión, Goldbach: Keip Verlag, 2001.

WILENMANN, Javier, "El sistema de graduación de la pena del homicidio en el derecho chileno", Politica Criminal, Vol. 11, N²2 (2016), pp. 721-765.

WILLIAMS, Glanville, "The Definition of Crime", Current Legal Problems, Vol. 8, N 1 (1955), pp. 107-130.

ZIPF, Heinz, Die Strafzumessung, Heidelberg/Karlsruhe: C.F. Müller, 1977. 